\title{
UNA COYUNTURA QUE CONMOCIONÓ A COLOMBIA: EL CONFLICTO CON EL PERÚ. \\ PERCEPCIONES EN EL ARCHIVO DE CARLOS E. RESTREPO (1932-1934)
}

\author{
Andrés López Bermúdez ${ }^{1}$ \\ Universidad de Antioquia \\ Marisol Valle Graciano ${ }^{2}$ \\ Universidad de Antioquia \\ DOI: 10.17533/udea.tempus.n6a04
}

\section{Resumen}

Estas líneas aportan una mirada certera a una coyuntura histórica significativa en el plano de las relaciones internacionales, la definición de la nacionalidad y el nacionalismo colombianos: el Conflicto colombo-peruano -y sus secuelas- entre 1932 y 1934. Dado el ascendiente político y el nivel de relaciones personales de Carlos E. Restrepo, expresidente colombiano y reconocido dirigente empresarial e intelectual en la época, su correspondencia registra una amplia gama de percepciones - de círculos decisorios y gentes del común-, que plasman un espontáneo sentimiento colectivo de rechazo frente a la eventual pérdida de soberanía nacional sobre vastos territorios fronterizos.

Palabras clave: Soberanía, patriotismo, nacionalismo, ciudadanía, identidad.

\section{Abstract}

These lines give a clear look at a significant historical conjuncture in the sphere of international relations, the definition of Colombian nationality and nationalism: the Colombo-Peruvian Conflict -and its aftermaths- between 1932 and 1934. Given the political ascendancy and the level of relationships of Carlos E. Restrepo, former Colombian president and recognized business and intellectual leader at that time, his correspondence registers a wide range of perceptions -of decision-making circles and people of the common-, that

\footnotetext{
1 Doctor en Historia. Profesor Titular, departamento de Historia, Universidad de Antioquia. andres.lopezb@udea.edu.co.

${ }^{2}$ Historiadora. marisolvalleg@ hotmail.com
} 
reflect a spontaneous collective feeling of rejection against the eventual loss of national sovereignty over vast border territories.

Keywords: Sovereignty, patriotism, nationalism, citizenship, identity.

\section{Presentación.}

El presente texto concentra su atención en el acervo documental constituido por la correspondencia que con relación al Conflicto colombo-peruano (1932-1934) reposa en el Archivo personal de Carlos E. Restrepo Restrepo (A/CER), ubicado en la Biblioteca Central de la Universidad de Antioquia, Medellín, en sus fondos Correspondencia Enviada (CE) y Correspondencia Recibida (CR). Relevante en el plano nacional de la primera mitad del siglo XX, este personaje se desempeñó como presidente de Colombia entre 1910 y 1914. Durante su mandato, aconteció una fugaz escaramuza en el sitio de La Pedrera entre el 10 y el 12 de julio de 1911, Intendencia del Caquetá, territorio cuya integración a la soberanía del Perú había sido pretendida por ese país desde el siglo XIX. Dicha circunstancia avivó la vieja animosidad sostenida por ambos Estados con relación a la soberanía exclusiva sobre los amplios territorios fronterizos. Años después, entre agosto de 1930 y julio de 1931, la vida pública de Carlos E. Restrepo se concentró en su actuación como ministro del Interior durante el mandato del presidente Enrique Olaya Herrera (1930-1934) ${ }^{3}$. A solicitud de éste, Restrepo pasó a oficiar luego como ministro plenipotenciario ante la Santa Sede, en Roma, encargo en el que se vio precisado a lidiar durante 1932, una vez más, con las repercusiones ocasionadas dentro y fuera de Colombia por la intempestiva ocupación armada de que fue objeto la ciudad fronteriza de Leticia, capital de la Comisaría colombiana del Amazonas, el $1^{\circ}$ de septiembre de 1932 por un grupo armado de 250 peruanos -58 de los cuales vestían de civil-, empeñados en anexionarla a su país ${ }^{4}$.

Por el ascendiente político de Restrepo y el nivel de sus relaciones personales con círculos decisorios colombianos, su Archivo constituye un acervo autorizado para auscultar

\footnotetext{
${ }^{3}$ Andrés González Díaz, "Ministros bajo la presidencia de Enrique Olaya Herrera", Ministros del siglo XX. Primera parte, consultado el 14 de diciembre de 2016. http://www.banrepcultural.org/blaavirtual/todaslasartes/obrames/ministros/ministros13.htm.

${ }^{4}$ Pedro Arciniegas Rueda, "Triunfo militar, empate diplomático", Revista Semana, 1 de septiembre de 2012, consultada el 16 de agosto de 2015. http://www.semana.com/nacion/articulo/triunfo-militar-empatediplomatico/263965-3.
} 
una coyuntura histórica significativa no sólo en el plano de las relaciones internacionales, sino también en lo atinente a la definición -y redefinición- de la nacionalidad y el nacionalismo colombianos. En efecto, el Conflicto colombo-peruano acaecido entre 1932 y 1934 conllevó la modificación de las nociones entonces sostenidas con relación a aspectos como la soberanía estatal, el patriotismo ciudadano, el nacionalismo y la identidad. Esto más allá de cualquier proceso propagandístico -indistintamente fomentado por todo Estado nacional en aras de fortalecerse-, pues frente a la toma territorial realizada por el Perú no sólo los políticos sino las gentes del común expresaron un espontáneo y avasallador sentimiento colectivo de rechazo, que suscitó el más amplio respaldo al gobierno de Colombia. En el Archivo del expresidente Carlos E. Restrepo, de otra parte connotado empresario e intelectual, se conservan múltiples testimonios ilustrativos del sentimiento descrito, así como del desarrollo del conflicto mismo mientras fue atendido por el Estado central. Aquellos testimonios exponen bien el fenómeno indicativo de cuánto, en medio de la coyuntura, importaba ser y sentirse colombiano. En concordancia con las fuentes consultadas, este trabajo centra su mirada en posturas y consideraciones adoptadas por personalidades diversas, que de una u otra manera manifestaron su sensibilidad ante la confrontación. Sus apreciaciones quedaron plasmadas en la correspondencia que sostuvieron con Restrepo, convocado también por el asunto, legando a la posteridad llamativos puntos de vista.

Por tanto, inicialmente se expondrán aquí observaciones analíticas -y sucesos expresivos- del antagonismo colombo-peruano, de manera que dichas referencias permitan comprender, en perspectiva amplia, la coyuntura abordada. Luego se toma en cuenta una detenida revisión documental efectuada sobre el Archivo de Carlos E. Restrepo, que como eje panorámico describe la postura general de círculos políticos, empresariales -e incluso intelectuales- en Colombia. Sabido es que las opiniones van generando efectos sociopolíticos, a medida que la progresión del acontecer histórico va perfilando situaciones precisas. En el caso del Conflicto colombo-peruano el examen de muy variadas opiniones evidencia que, sus repercusiones históricas inmediatas, sólo contaron con una recordación vital -unificadora y trascendente- más bien efímera. El presente trabajo se exime así de pretensiones mayores, tales como detallar de manera rigurosa la evolución de los 
acontecimientos, objeto de estudio válido pero profusamente abordado por otras investigaciones.

\section{Acontecimientos y versiones de la historia escrita.}

La historia escrita colombiana suele hacer énfasis en que el Estado colombiano ha ejecutado sus pactos diplomáticos de manera recta, gestionando acuerdos con limpieza y pudor. Insiste en que los problemas con el Perú acaecidos entre 1932 y 1934, no estuvieron exentos de esa postura. Igualmente, expone que el gobierno colombiano hizo lo posible para negociar éticamente cuando aconteció el conflicto, reclamando para ello ante organismos internacionales derechos previamente adquiridos.

Las disputas entre Colombia y Perú son de vieja data. Así lo indicó José Manuel Restrepo en 1827, cuando anotó que el ejecutivo peruano perseguía a los comisionados colombianos e interceptaba sus comunicaciones. Según anotó, el Perú no dudó entonces en reforzar su ejército para enfrentar a Simón Bolívar, quien, cansado de esos insultos solicitó “una satisfacción", reclamo que por poco genera una guerra ${ }^{5}$. Ese tipo de posturas manifestadas por los historiadores colombianos, concuerdan casi por completo con las opiniones que reposan en el Archivo personal del expresidente Carlos E. Restrepo. Así por ejemplo, mientras residía en Roma en 1933, expresó: “Que nación ésta [-el Perú-] y cómo parece que Dios la hubiera dotado desde la cuna de todos los gérmenes de la perfidia. Nosotros debemos combatirla hasta restablecer nuestro derecho o nos borren del mapa"6. Días después expresó al ministro de Relaciones Exteriores de Colombia, Roberto Urdaneta Arbeláez, que imaginaba cuán grandes eran los apuros para hacer frente a las estratagemas y deslealtades peruanas, pues según sabía "sus asechanzas y su mala fe" eran frecuentes desde la época de Simón Bolívar ${ }^{7}$. Desde su perspectiva, los peruanos se encontraban distanciados de una postura en rigor diplomática, mientras que la asumida por Colombia se caracterizaba "por la gallardía y la corrección de actitud" 8 . Esta misma percepción le fue compartida a

\footnotetext{
${ }^{5}$ José Manuel Restrepo, Diario político y militar, Tomo I (Bogotá: Imprenta Nacional, 1954), 369.

${ }^{6}$ Carta de Carlos E. Restrepo a Marco Tulio Pérez, Roma, 7 de enero de 1933, A/CER/CE 74A/174: 298.

7 Carta de Carlos E. Restrepo a Roberto Urdaneta Arbeláez, Roma, 12 de enero de 1933, A/CER/CE 74A/240:400.

${ }^{8}$ Carta de Carlos E. Restrepo a Roberto Urdaneta Arbeláez, Roma, 5 de septiembre de 1932, A/CER/CE 74A/22:26.
} 
Restrepo por su amigo Jaime Holguín - personaje dedicado a la banca9 - quien le comentó: "a vencer nadie está obligado, pero sí a no cometer el menor acto indecoroso ni que tenga la menor sombra de ello"10. El mismo pensamiento se manifestó de nuevo cuando el expresidente escribió a Eduardo Santos - connotado dirigente liberal y periodista colombiano, jefe de misión diplomática ante los Estados de Europa y ante la Sociedad de las Naciones ${ }^{11}$ , que cualquier negociación con el Perú debía ser prudente y moderada, porque "no cumplir después de ofrecer" no constituía una actitud acorde con las tradiciones diplomáticas, caracterizadas en el caso de Colombia por siempre haberse demostrado "demasiado limpias" $" 12$.

El Conflicto terminó gracias a un Acuerdo firmado en Ginebra el 26 de mayo de 1933, que resolvió que Leticia quedaría durante un año a disposición de una comisión internacional, designada por la Sociedad de las Naciones para ejercer administración en nombre de Colombia $^{13}$. Entonces Bogotá argumentó una necesaria unidad entre americanos, con el objeto de no arriesgar la paz suscrita ${ }^{14}$. Terminada la contienda Colombia alcanzó ciertos honores internacionales, derivados del manejo dado al evento. Destacó la que consideraba una actitud justa de su parte en el marco del derecho de las naciones, cuyo reconocimiento le granjeó de hecho una corriente favorable -a juicio de Restrepo- en el ámbito jurídico internacional ${ }^{15}$. En síntesis, la opinión general de la diplomacia colombiana manifestada después de la rúbrica del Protocolo de Río (del 24 de mayo de 1934, con el propósito expreso de ratificar el Tratado Salomón Lozano del 24 de marzo de 1922, que desde entonces mantiene estables los límites entre ambos países) ${ }^{16}$, se recoge una aseveración expresada por

\footnotetext{
${ }^{9}$ Enrique Santos Molano, "La Misión Kemmerer", Credencial Historia no. 184 (abril de 2005), consultada el 15 de diciembre de 2015. http://www.banrepcultural.org/blaavirtual/revistas/credencial/abril2005/mision.htm ${ }^{10}$ Carta de Jaime Holguín a Carlos E. Restrepo, Bogotá, 10 de febrero de 1933, A/CER/CR 74B/81:113.

${ }^{11}$ Organismo internacional antecedente de la ONU, creado por el Tratado de Versalles en 1919 con sede en Ginebra, Suiza. Santos sería uno de los diplomáticos que aceptaría y suscribiría en 1933 el acuerdo que puso término al Conflicto. Después desempeñó varios cargos, entre ellos la presidencia de la República (1938-1942). Oliverio Perry, Quién es quién en Colombia (Bogotá: Perry Oliverio \& Cía. Editores. Argra, 1961), 237.

${ }^{12}$ Carta de Carlos E. Restrepo a Eduardo Santos, Roma, 22 de diciembre de 1932, A/CER/CE 74A/194:331.

${ }^{13}$ Guillermo Plazas Olarte, "Conflicto con el Perú, 1932-1934”, Historia de las fuerzas militares de Colombia, tomo III (Bogotá: Planeta, 1993), 47.

${ }^{14}$ Carta de Eduardo Santos al secretario general de la Sociedad de las Naciones, Ginebra, 18 de marzo de 1934, $\mathrm{A} / \mathrm{CER} / \mathrm{CR}$ 75/229:326.

${ }^{15}$ Carta de Diego José Fallon a Carlos E. Restrepo, Chicago, 5 de abril de 1933, A/CER/CR 74B/10:13.

${ }^{16}$ República de Colombia. Protocolo de Río de Janeiro. Texto del protocolo. Proyecto de Ley y exposición de motivos (Bogotá, Imprenta Nacional, 1934), 31.
} 
Carlos E. Restrepo a su amigo Fabio Lozano Torrijos (firmante por Colombia del Tratado Salomón-Lozano de 1922), alusiva a un libro publicado por este último: "es una monografía completa de nuestras relaciones diplomáticas con el Perú, y las del Perú para con nosotros tan poco diplomáticas" ${ }^{\prime 17}$.

Años después el diplomático colombiano José Joaquín Caicedo Castilla validaría esta mirada, argumentando que la política internacional de su país había brillado históricamente, dado el respeto a la jurisprudencia y a la soberanía de otros Estados ${ }^{18}$. Tales palabras expresan una tradición presente en la historia escrita que, a la par de la diplomática, asumen una perspectiva casi unánime, avivada entre otros por el ministro de Relaciones Exteriores Luis López de Mesa en 1942, cuando afirmó: "Colombia es una potencia moral"19. Refiriéndose a la posición asumida por Colombia en el marco del Conflicto colombo-peruano, la investigadora Sandra Milena Hernández destaca que, históricamente, en efecto, el país procuró adelantar sus relaciones externas respetando de manera rigurosa el derecho internacional, es decir, intentando caminos diplomáticos de manera invariable. Así por ejemplo, se acogió a la normatividad de la V Conferencia Panamericana realizada en Chile el 3 de mayo de 1923, también aceptada por el Perú, según la cual la prevención de ocasionales dificultades entre Estados requería el estudio de salidas negociables, por parte terceros países independientes. Años después, el 27 de agosto de 1928, en el Tratado BriandKellogg suscrito en París en apoyo de los programas de la Sociedad de las Naciones, Perú y Colombia renunciaron al uso de las armas para finiquitar desacuerdos. Posteriormente, el 3 de agosto de 1932, firmaron en Washington una declaratoria que condenó la obtención territorial apelando a la violencia. Previamente, el 10 de diciembre de 1924, el representante peruano ante la Sociedad de las Naciones había declarado que su país renunciaba al uso de la fuerza como principio, pronunciamiento aplaudido desde Ginebra por el delegado colombiano ante la misma entidad. Esta clase de determinaciones pone de presente que, en el periodo posterior a la Primera Guerra Mundial, prevalecía un ambiente belicista y de tensión general, situación que en Colombia precipitó la búsqueda de opciones jurídicas

\footnotetext{
${ }^{17}$ Carta de Carlos E. Restrepo a Fabio Lozano Torrijos, Roma, 25 de mayo de 1934, A/CER/CE 75/155:209.

18 José J. Caicedo Castilla, "Historia Diplomática", Historia extensa de Colombia, vol. XVII (Bogotá: Lerner, 1974), 18.

${ }^{19}$ Luis López de Mesa, "Breve comentario inicial”, Historia de la cancillería de San Carlos (Bogotá: Imprenta del Estado Mayor General, 1942), 86.
} 
procurando prevenir posibles conflictos. Así, este país manifestó expresamente el cumplimiento y la atención a los citados acuerdos, circunstancia que la condujo a actuar con prudencia cuando se suscitó la agresión del Perú a la ciudad limítrofe de Leticia en $1932^{20}$.

\section{La difícil coexistencia binacional.}

Conforme se ha expuesto Colombia y Perú manifestaron diferencias en diversas oportunidades, llegando a circunstancias próximas a una confrontación antes de 1932. Los ejemplos más relevantes obligan a mencionar la Batalla del Portete de Tarqui, cerca de Cuenca (actual Ecuador), lugar en donde el 27 de febrero de 1829 se enfrentaron los generales peruanos José María Plaza y José de La Mar con los ejércitos grancolombianos comandados por Antonio José de Sucre y Juan José Flores, obteniendo la victoria estos últimos para exigir luego la evacuación de territorios ocupados en la provincia del Azuay. Casi una centuria después, entre el 10 y el 12 de julio de 1911, se produjo un combate en el sitio de La Pedrera, ubicado sobre la margen derecha del río Caquetá, actual Departamento del Amazonas (Colombia), donde 480 soldados peruanos comandados por el coronel Óscar Benavides vencieron a una tropa colombiana de 50 efectivos encabezada por el general Isaías J. Gamboa, quien sólo pudo resistir la ofensiva durante tres días ${ }^{21}$. Sin embargo, el 23 de octubre de ese año por iniciativa del delegado colombiano en Lima, Eduardo Restrepo Sáenz, la zona pudo recuperarse por vía diplomática ${ }^{22}$. Los problemas fronterizos parecieron finalizar gracias a la firma del Tratado Salomón-Lozano en 1922, que estableció que Colombia reconocía al Perú plena soberanía sobre "los territorios comprendidos entre la margen derecha del río Putumayo, hacia el oriente de la boca del Cuhimbé, y la línea establecida y amojonada como frontera entre Colombia y el Ecuador en las hoyas del Putumayo y del Napo, en virtud del Tratado de Límites celebrado entre ambas Repúblicas,

\footnotetext{
${ }^{20}$ Sandra Milena Hernández Rodríguez, “Análisis de las estrategias de actores nacionales e internacionales en la firma de los acuerdos diplomáticos suscritos entre Perú y Colombia en 1934 y su incidencia en la resolución del conflicto bilateral", Monografía de grado para optar al título de Internacionalista, Facultad de Relaciones Internacionales, Universidad Colegio Mayor de Nuestra Señora del Rosario (Bogotá, 2010), 13.

${ }^{21}$ Sin firmar. "Las guerras con el Perú", Credencial Historia no. 191 (noviembre de 2005), consultado el 15 de diciembre de

2015. http://www.banrepcultural.org/blaavirtual/revistas/credencial/noviembre2005/guerras_peru.htm.

22 Pedro Arciniegas Rueda, “Triunfo militar, empate diplomático".
} 
el 15 de julio de 1916"23. El Tratado Salomón-Lozano fue promocionado después por Colombia ante la opinión internacional, argumentando su idoneidad como ejemplo de civilización y de entendimiento.

Una década después retornaron los desacuerdos, cuando el $1^{\circ}$ de septiembre de 1932 , doscientos cincuenta peruanos armados irrumpieron en la ciudad de Leticia, reduciendo la irrisoria tropa colombiana, saqueando el peculio oficial, e izando su bandera bajo el argumento de poseer derechos sobre la zona ${ }^{24}$. Para denunciar la situación, el gobierno colombiano nombró en Europa a Eduardo Santos con el cargo de embajador extraordinario y plenipotenciario, quien ante la Sociedad de las Naciones procuró se reconociera el Tratado firmado en $1922^{25}$. Según el investigador Pedro Arciniegas Rueda, la intrusión peruana precipitó en toda Colombia un éxtasis patriótico que clamaba por una guerra, ocasionado colectas voluntarias que aportaron ingentes cantidades de argollas de matrimoniales, escuadras militares integradas por estudiantes de universidades bogotanas, y batallones conformados en Pasto con los nombres de "Boyacá" y "Colombia". En Norteamérica se presentaron voluntarios ante los consulados, y los marinos sanandresanos ofrecieron navíos mercantes para servir a Colombia. Por su lado, el Partido Comunista se opuso abiertamente a la disputa ${ }^{26}$.

El 14 de enero de 1933 una flotilla colombiana recorrió el río Putumayo con destino al puerto de Tarapacá, convoy comandado por el general Efraín Rojas con el propósito de ocupar ese lugar antes que a Leticia, con la intención de darle tiempo a los peruanos de aceptar la invitación a evacuar formulada por el canciller brasilero Afranio de Mello Franco, evitando un choque armado. El 27 de ese mes, la Sociedad de las Naciones reconoció que Colombia tenía plena autoridad sobre su territorio. El 14 de febrero, el general Rojas envió con el subteniente Jorge Hernández una nota al teniente peruano -y comandante del puertoGonzalo Díaz, sugiriéndole entregar pacíficamente. En respuesta, las fuerzas peruanas

\footnotetext{
${ }^{23}$ Alberto Salomón y Fabio Lozano Torrijos, Tratado de Límites y Navegación Fluvial entre las Repúblicas de Colombia y Perú (Tratado Salomón-Lozano) (Bogotá: Imprenta Nacional, 1979); Artículo 1, Sociedad Geográfica de Colombia, consultada el 15 de diciembre de 2015. http://www.sogeocol.edu.co/Ova/fronteras_evolucion/documentos/arreglo_limites_colombia_peru.pdf

${ }^{24}$ Pedro Arciniegas Rueda, "Triunfo militar, empate diplomático".

${ }^{25}$ Jorge Mario Eastman, (Comp.) "Eduardo Santos", Obras selectas (Bogotá: Fondo de publicaciones de la Cámara de Representantes, 1981), 19.

${ }^{26}$ Pedro Arciniegas Rueda, "Triunfo militar, empate diplomático".
} 
bombardearon los navíos colombianos. Ello precipitó una contraofensiva aérea dirigida por el coronel Luis Acevedo, en cooperación con contingentes fluviales que retomaron el lugar el día 15, sin perder vida alguna ${ }^{27}$. Estos hechos rompieron definitivamente las relaciones diplomáticas y marcaron el inicio del Conflicto armado ${ }^{28}$. Otro foco del enfrentamiento se presentó en Güepí, cuya ofensiva fue adelantada por la Armada colombiana desde Puerto Asís (actual Departamento del Putumayo) a partir del 24 de marzo de 1933. Para el día 26 Colombia obtuvo una primera victoria, que reafirmó las posiciones políticas en la Sociedad de las Naciones, arguyendo la vigencia de la soberanía. En opinión del general e historiador colombiano Álvaro Valencia Tovar, con todo ello "un país que demostraba suficiencia militar para definir el conflicto por las armas, [también] insistía en la solución pacífica" ${ }^{29}$. El 26 de mayo de 1933 se rubricó el Acuerdo de Ginebra, que dictaminó que Leticia sería administrada durante un año para Colombia, por una delegación internacional elegida por la Sociedad de las Naciones. Durante ese lapso las tropas colombianas debían abandonar a Güepí y otros puertos arrebatados a los peruanos sobre el río Putumayo ${ }^{30}$. La comisión administradora de Leticia quedó integrada entre otros por el coronel estadounidense Artur Brown, el capitán del ejército brasilero Alberto Lemos Bastos, y el capitán de la Fuerza Aérea Española Francisco Iglesias. Luego esa junta solicitó al ejército colombiano facilitar un contingente de 150 hombres, que se apostó en la zona bajo las órdenes del coronel Luis Acevedo. Posteriormente, el 24 de mayo de 1934 por recomendación de la Sociedad de las Naciones, se formalizó el Protocolo de Río de Janeiro (Brasil), cuyos representantes por Colombia fueron el canciller Roberto Urdaneta Arbeláez, el político y poeta Guillermo Valencia, y el periodista Luis Cano Villegas. Por el Perú participaron Víctor Maúrtua, Víctor A. Belaúnde y Alberto Ulloa. Ambas partes contaron con la intervención del canciller del Brasil Afranio de Mello Franco. En el encuentro se firmaron convenios de ayuda, afecto y armonía entre ambos Estados. Los

\footnotetext{
27 Biblioteca Virtual Luis Ángel Arango. "Combate de Tarapacá”, consultado el 25 de noviembre de 2013. http://www.banrepcultural.org/node/98004.

${ }^{28}$ Sandra Milena Hernández Rodríguez, “Análisis de las estrategias de actores nacionales e internacionales en la firma de los acuerdos diplomáticos suscritos entre Perú y Colombia en 1934...", 24.

${ }_{29}$ Álvaro Valencia Tovar, "Historia militar contemporánea", en Nueva Historia de Colombia, vol. II, (Dir.) Álvaro Tirado Mejía (Bogotá: Planeta, 1989), 323.

${ }^{30}$ Pedro Arciniegas Rueda, "Triunfo militar, empate diplomático".
} 
peruanos lamentaron la guerra y reconocieron la vigencia del Tratado Salomón-Lozano de $1922^{31}$.

\section{El conflicto ante círculos políticos, empresariales e intelectuales colombianos.}

Las páginas siguientes concentrarán su mirada sobre múltiples declaraciones proferidas acerca de la confrontación por personalidades diversas, dotadas en aquel entonces de prestancia política, económica, social e intelectual. Con sus pronunciamientos, plasmaron elementos útiles para ilustrar variadas evoluciones y sesgos.

La guerra comenzó el $1^{\circ}$ de septiembre de 1932. A mediados de ese mes la invasión se había convertido ya en un suceso que colmaba la atención noticiosa del hemisferio. Por esos días, Colombia comenzaba a recobrarse de la Gran Depresión Mundial de 1929. Al principio se pensó que la confrontación se solucionaría prontamente, pero declaraciones belicistas del general Sánchez Cerro, presidente del Perú, plantearon la posibilidad de una acción armada prolongada y destructiva. Como vía alterna, un segmento de la opinión pública colombiana propuso apelar al derecho internacional para demostrar la inconsistencia de las pretensiones peruanas, en términos jurídicos y geográficos, dada la preexistencia del Tratado de 1922. Este camino otorgaba prelación al uso de métodos racionales, a fin de prevenir una sumatoria de efectos devastadores, que, en consideración de la correlación de fuerzas, podrían afectar negativamente a Colombia ${ }^{32}$. Otro sector de la opinión pública, consideraba que la confrontación armada constituía un sendero que inevitablemente habría que recorrer. Para quienes así opinaban, había que acudir a las armas porque, al menos en parte, las denuncias formuladas por personajes (como el periodista peruano Benjamín Saldaña Rocca $^{33}$, o los británicos Walter E. Hardenburg ${ }^{34}$, Roger Casement ${ }^{35}$ y Norman Thomson ${ }^{36}$ ) alusivas a la violencia extrema ejercida sobre poblaciones indígenas de la frontera por parte

\footnotetext{
31 Guillermo Plazas Olarte, "Conflicto con el Perú, 1932-1934”, 47. Cf. además: República de Colombia, Protocolo de Río de Janeiro. Texto del protocolo. Proyecto de Ley y exposición de motivos (Bogotá: Imprenta Nacional, 1934).

32 Pedro Arciniegas Rueda, "Triunfo militar, empate diplomático".

33 Fernando Najar, "Benjamín Saldaña en el recuerdo", consultado el 14 de noviembre de 2013. http://diariodeiqt.wordpress.com/2009/04/15/benjamin-saldana-en-el-recuerdo/

${ }^{34}$ Walter E Hardenburg, El paraíso del diablo (Londres: Editorial F. Truth, 1909), 103.

${ }^{35}$ Roger Casement, El libro azul británico. Informes de Roger Casement y otras cartas sobre las atrocidades en el Putumayo (Londres: Editorial IWGIA, 1912), 245.

${ }^{36}$ Norman Thomson, El Libro Rojo del Putumayo (Bogotá: Arboleda\&Valencia, 1913), 130.
} 
de compañías caucheras como la Casa Arana -peruana-, o la Peruvian Amazon Co. británica-, habían resultado infructuosas. Si bien el citado periodista y funcionarios enviados por el Parlamento Británico habían puesto de presente las atrocidades genocidas contra los aborígenes de la región, aquellas declaraciones habían logrado un efecto escaso. Incluso una obra literaria colombiana como La Vorágine, novela de José Eustasio Rivera (1924), había reflejado la misma situación sin conseguir poner freno a las atrocidades ${ }^{37}$. Como fuere, partícipes de una y otra opinión expresaron su apoyo al gobierno colombiano en la tentativa de solucionar las diferencias binacionales.

Viejas heridas se encontraban presentes, pues recuerdos como las nefastas consecuencias de la Guerra civil de los Mil Días (1899-1902), la pérdida de Panamá (3 de noviembre de 1903), o la maltrecha retirada de las tropas colombianas apostadas en el sitio de La Pedrera (10 al 12 de julio de 1911) no habían sanado todavía. En ese sentido, el reconocido académico y escritor antioqueño Saturnino Restrepo ${ }^{38}$ le expresó a su amigo Carlos E. Restrepo, que, a su juicio, la guerra con el Perú constituía "la mayor calamidad que hayamos tenido desde Panamá y sin ninguna compensación directa o indirecta que prometerse"39. Así mismo el jurista, exsecretario del Tesoro (de 1910 a 1914) y Representante a la Cámara (1930-1934) Ricardo Hinestrosa Daza ${ }^{40}$, se comunicó con Restrepo para manifestarle cómo en medio de "la honda emoción de estas horas que a la vez son de la más alta elación patriótica y de la mayor angustia", había "revivido los dolorosos y agitados días de La Pedrera", dada la "nueva agresión que a Colombia hace la tradicional perfidia peruana" ${ }^{\prime 1}$. Dicha perfidia aparece señalada repetidas comunicaciones entonces dirigidas a Restrepo por variadas personalidades. Así por ejemplo, en misiva que le fue remitida por su gran amigo, el comerciante y banquero Luis M. Escobar ${ }^{42}$, la postura del Perú

\footnotetext{
37 José Eustasio Rivera, La Vorágine (Bogotá: El Áncora Editores, 1989), 96.

${ }^{38}$ Javier Mejía Cubillos, Diccionario biográfico y genealógico de la élite antioqueña y viejocaldense (Medellín: Universidad de Antioquia, Departamento de Economía, 2011), 117.

39 Carta de Saturnino Restrepo a Carlos E. Restrepo, Estocolmo, 5 de noviembre de 1932, A/CER/CR 74A/181:308.

${ }^{40}$ Fernando Villa Quintero, “Hinestrosa Daza, Ricardo”, en Gran Enciclopedia de Colombia, Vol. 17, (Dir.) Fernando Wills Franco (Bogotá: Casa Editorial El Tiempo - Círculo de Lectores, 2007), 118-119.

${ }^{41}$ Carta de Ricardo Hinestroza Daza a Carlos E. Restrepo, Bogotá, 20 de septiembre de 1932, A/CER/CR 74A/91:151.

${ }^{42}$ Javier Mejía Cubillos, Diccionario biográfico y genealógico de la élite antioqueña y viejocaldense, 94.
} 
era valorada como una especie de recurrente expansionismo o "imperialismo inglés", que se consideraba tradicionalmente había pretendido ejercer sobre sus vecinos, y abiertamente sobre Colombia ${ }^{43}$. Paralelamente, el dirigente político y empresarial de Santa Marta Florentino Goenaga ${ }^{44}$, resaltó en nota dirigida a Restrepo que los peruanos tal vez aspiraban a obtener el título de "japoneses de América", a lo que añadió: "Si Colombia no vuelve por su prestigio, será mostrada con el dedo como nación incapaz de defender la integridad de su territorio" 45 . Como puede observarse, múltiples colombianos de ámbitos tan diversos como el periodístico, el académico, el intelectual, el jurídico, el político o el comercial -entre otros, se comunicaron con el expresidente para expresarle puntos de vista que acogían una postura genuinamente nacional y patriótica, centrada en el propósito de afrontar la situación del momento.

Considerando el gran esfuerzo económico que para el país representaba el sostenimiento de una guerra, el citado Hinestrosa Daza agregó que, sin embargo, el Conflicto consiguió suscitar exaltados bríos en toda Colombia, uniendo bajo un solo ideal a eternos rivales en el campo partidista, hasta entonces persistentemente proclive a propiciar mutuas hostilidades en el seno del parlamento ${ }^{46}$. Siguiendo ese orden de ideas, otro corresponsal de Restrepo, el señor Eustasio Camargo -de quien no ha sido posible obtener datos adicionales, le señaló que el Conflicto conllevaba cierto provecho providencial, puesto que daba lugar a que las facciones partidistas morigeraran sus luchas tradicionales, siempre mantenidas en pro del control político, pero jamás en función de benéficas conquistas éticas ${ }^{47}$. Indicó Camargo, que la concordia nacional acarreada en primera instancia por el Conflicto, se vio luego lamentablemente suspendida, pues pasados algunos meses de exaltación patriótica ésta no se mantuvo, derivando de nuevo, como cabría esperar, en un infructuoso y desmotivante influjo partidista $^{48}$. El Archivo de Carlos E. Restrepo muestra en efecto cómo en la esfera política

\footnotetext{
${ }^{43}$ Carta de Luis M. Escobar a Carlos E. Restrepo, Medellín, 21 de octubre de 1932, A/CER/CR 74A/44:30.

44 Segismundo del Real de Gandía, La Sierra Nevada y los orfelinatos de La Guajira (Bogotá: Imprenta Nacional, 1912), 56-57.

${ }^{45}$ Carta de Florentino Goenaga a Carlos E. Restrepo, Santa Marta, 24 de diciembre de 1932, A/CER/CR 74A/47:93.

${ }^{46}$ Carta de Ricardo Hinestroza Daza a Carlos E. Restrepo, Bogotá, 20 de septiembre de 1932, A/CER/CR 74A/91:151.

${ }^{47}$ Carta de Eustasio Camargo a Carlos E. Restrepo, Manizales, 12 de diciembre de 1932, A/CER/CR 74A/10:10.

${ }^{48}$ Carta de Eustasio Camargo a Carlos E. Restrepo, Sogamoso, 28 de abril de 1933, A/CER/CR 75/50:66.
} 
colombiana, los ímpetus partidistas nunca desaparecieron por completo, ni siquiera en aquellos momentos en que los intereses generales demandaban un consenso total.

Entre tanto, Eduardo Santos ponía de presente que la opinión internacional comenzaba a evidenciar escasa capacidad de defensa de los intereses legales del país, obligando así a los colombianos a batallar con sus propios recursos por la recuperación de Leticia. Términos similares empleó el escultor Marco Tobón Mejía a su mecenas Restrepo, en otra comunicación ${ }^{49}$. Esta opinión alcanzó gran resonancia para los primeros días de febrero de 1933, como también lo indicó el general y periodista Jorge Martínez a su amigo Restrepo $^{50}$, cuando le aseveró que, aunque el gobierno peruano desconocía un Tratado previamente validado por dos naciones, tal situación determinaba un triunfo para Colombia -al menos en el terreno jurídico-, sin importar las enormes dificultades que militarmente se encontrara compelida a sortear para confirmar ante la opinión internacional una postura digna: "y si los hados militares nos fueren adversos, el honor queda a salvo y este aunque no sea nada para un peruano es bastante para los colombianos" 51 . En el Archivo de Restrepo reposan interesantes percepciones proferidas por otros personajes que, de manera sentida, ofrecieron su irrestricto apoyo a Colombia durante el conflicto. El primero, al parecer un extranjero, remitió su carta firmándola simplemente con las iniciales "W.N.”. Allí indicó encontrarse resuelto a entregar su vida en defensa de una nación a la que consideraba, según dijo, su segunda patria, ya que durante muchos años había residido en ella, e incluso contraído nupcias $^{52}$. Personaje adicional fue el ingeniero e intelectual de la élite barranquillera Bonifacio Faillace ${ }^{53}$, paradójicamente por entonces cónsul general del Perú en Torino (Italia),

${ }^{49}$ Carta de Marco Tobón Mejía a Carlos E. Restrepo, París, 20 de enero de 1933, A/CER/CR 74B/261:364.

50 Jorge Martínez Landínez había sido cercano a Restrepo al menos desde 1910, cuando se destacó como connotado defensor de la libre expresión escrita y promotor de la candidatura presidencial de Restrepo por el Partido Republicano. Maryluz Vallejo M., "El Grito de Irreverencia del Gil Blas", Revista de Estudios Sociales no. 38 (enero de 2011): 76-80.

${ }^{51}$ Carta de Jorge Martínez Landínez a Carlos E. Restrepo, Manizales, 2 de febrero de 1933, A/CER/CR 74B/50:70.

${ }^{52}$ Carta de W. N. a Carlos E. Restrepo, Brescia, 21 de marzo de 1933, A/CER/CR 74B/159:217.

${ }^{53}$ Albio Martínez Simanca, José Félix Fuenmayor. Entre la tradición y la vanguardia (Bogotá: Observatorio del Caribe Colombiano, 2011), 51; Sergio Paolo Solano de las Aguas, Puertos, sociedad y conflictos en el Caribe colombiano, 1850-1930 (Bogotá: Observatorio del Caribe Colombiano-Universidad de Cartagena, 2003), 75. 
quien rechazó el accionar utilizado por ese país en el contexto suscitado por la confrontación ${ }^{54}$.

El gobierno nacional procuró impulsar planes que, a pesar de que las coyunturas fueron variando, consideró oportunos según el momento. Así, comenzando febrero de 1933 -cuando las reclamaciones de carácter diplomático se encontraban ya prácticamente consumadas-, centró su atención en la preparación de las estrategias bélicas necesarias, que para entonces resultaba imposible desconocer o retardar ${ }^{55}$. Sobre este asunto, el dirigente empresarial Florentino Goenaga, resaltó que el Perú no osaría jugar con Colombia nuevamente, tal como lo había hecho desde el siglo XIX, claro está, solo si el ejército colombiano adoptaba correctivos y precauciones pertinentes:

\begin{abstract}
Yo creo que el Perú es conocido desde los tiempos del zorro Lamar [-José de La Mar, presidente del Perú en 1827-] y Colombia no se dejará carameliar más. Los soldados colombianos han probado una vez más su tradicional intrepidez en los encuentros habidos, de modo que los peruanos, que los motejaban de cobardes, han llevado hasta ahora su merecido. Y al tiempo que Colombia protegía y atendía cortésmente al señor Carrillo, Ministro del Perú en Bogotá, los limeños asaltaban y saqueaban la legación de Colombia en el Perú, portándose como unos verdaderos salvajes $^{56}$.
\end{abstract}

En efecto, luego de una manifestación de protesta que desencadenó en disturbios y en el saqueo a la embajada colombiana en Lima por parte de ciudadanos peruanos, el 18 de febrero de 1933 la opinión pública colombiana reclamó con indignación el uso de la fuerza ${ }^{57}$. Así por ejemplo, el político y empresario Gonzalo Restrepo Jaramillo (sobrino de Carlos E. Restrepo), le escribió al expresidente recalcando que el país no podía permitirse el lujo de aceptar mutilaciones a su integridad por tiranos, puesto que el Amazonas constituía un foco de atención que era indispensable defender patrióticamente para el beneficio de "generaciones futuras" "58. Hablaba de tiranos aludiendo al caso concreto del mandatario del Perú Luis Miguel Sánchez Cerro. Al respecto Diego José Fallon -hijo del famoso poeta del siglo XIX Diego Fallon-, informó a su amigo Restrepo que mientras en Colombia el

\footnotetext{
${ }^{54}$ Carta de Bonifacio Faillace a Carlos E. Restrepo, Torino, $1^{\circ}$ de mayo de 1933, A/CER/CR 74B/8:10.

${ }_{55}^{55}$ Pedro Arciniegas Rueda, "Triunfo militar, empate diplomático".

${ }^{56}$ Carta de Florentino Goenaga a Carlos E. Restrepo, Santa Marta, 24 de febrero de 1933, A/CER/CR 74B/47:66.

${ }^{57}$ Alberto Donadío, "Colombia expulsa a los peruanos de Tarapacá", Colombia manía, consultado el 5 de diciembre de 2016. http://www.colombiamania.com/historia/index_historia/07_otros_hechos_historicos/0210_guerra_peru.html. ${ }^{58}$ Carta de Gonzalo Restrepo Jaramillo a Carlos E. Restrepo, Medellín, [sin fecha], A/CER/CR 74B/204:277.
} 
presidente Olaya Herrera recibía el apoyo enfático y ordenado de las gentes, el mandatario del Perú carecía por su parte de un apoyo popular siquiera comparable ${ }^{59}$. La voz de Fallon resultó profética, porque poco después, el 30 de abril de 1933, Sánchez Cerro fue asesinado por un militante comunista peruano, mientras que una significativa mayoría de colombianos agradecía a Olaya Herrera su accionar en pro de un exitoso desenlace del Conflicto ${ }^{60}$. Se consideró que el trabajo de Olaya Herrera fue oportuno sobre todo en lo relacionado con la confrontación exterior, y además, en lo atinente a su gestión política interna. Tales aciertos acreditaron de hecho su fortaleza como experimentado estadista.

El arribo del general Óscar R. Benavides a la presidencia del Perú el 30 de abril de 1933, como sucesor de Sánchez Cerro, fue acogido por los colombianos de manera positiva, puesto que el anterior mandatario era considerado como "un verdadero monstruo de proyecciones peligrosas para la paz de América", conforme lo anotó el empresario ${ }^{61}$ y yerno del expresidente Restrepo, Tulio Forero ${ }^{62}$. Sin embargo, a mediados de 1933 Colombia sintió en su economía la pesadez transferida por el Conflicto. A raíz de ello y dados los términos de la paz firmada en Ginebra, se produjo un clima adverso para el gobierno. Quienes lo respaldaban consideraban que tales diferencias no evidenciaban los términos del Tratado mismo, sino más bien malestares partidistas surgidos en los Departamentos de Bolívar, Santander y Boyacá, recelos usuales en la política nacional desde el siglo XIX. Reconocidos personajes que apoyaron al gobierno nacional, como por ejemplo el empresario Diego Martínez, -muy cercano a Carlos E. Restrepo en actividades del campo comercial ${ }^{63}$-, opinaron que, a pesar de que la administración adelantó sus gestiones de manera acertada, probablemente habría obtenido mejores resultados si el Partido Conservador la hubiese secundado o "ayudado con franqueza"64. Aunque Olaya Herrera hizo uso de sus atribuciones como presidente, no alcanzó a evadir conforme lo deseó las malquerencias y presiones de

\footnotetext{
${ }^{59}$ Carta de Diego José Fallon a Carlos E. Restrepo, Chicago, 5 de abril de 1933, A/CER/CR 74B/10:13.

${ }^{60}$ Pedro Arciniegas Rueda, "Triunfo militar, empate diplomático".

${ }^{61}$ Jorge Cavelier Gaviria, "Clínica Marly: 90 años de servicio al país”, El Tiempo, Bogotá, 18 de febrero de 1994, consultado el 5 de diciembre de 2016. http://www.eltiempo.com/archivo/documento/MAM-44946.

${ }^{62}$ Carta de Tulio Forero a Carlos E. Restrepo, Ibagué, 3 de mayo de 1933, A/CER/CR 74B/6:7.

${ }^{63}$ María Teresa Ripoll de Lemaitre, "La actividad empresarial de Diego Martínez Camargo, 1890-1937”, Cuadernos de Historia Económica y Empresarial no. 2 (1999): 21; y, María Teresa Ripoll de Lemaitre, "Diego Martínez Camargo, Pionero de la industria petrolera en el caribe colombiano", Huellas no.62 (2001): 27-28.

${ }^{64}$ Carta de Diego Martínez a Carlos E. Restrepo, Lorica, 23 de junio de 1933, A/CER/CR 74B/130:173.
} 
políticos regionales, -es decir, de "caciques" electorales-, que entorpecieron el flujo de relaciones vinculantes de las provincias con el Estado central. Una vez terminadas las acciones militares del Conflicto, entre aquellos políticos regionales se contaron, principalmente, el dirigente conservador Laureano Gómez y sus copartidarios integrantes del Parlamento José de la Vega y Augusto Ramírez Moreno ${ }^{65}$. Para los meses finales de 1933 la economía no se recobraba todavía. Opiniones como la expresada por Cipriano Restrepo Jaramillo (sobrino del expresidente Restrepo), sugirieron que el Brasil había entorpecido un arreglo con el Perú, dado que al primer país le resultaba conveniente la intranquilidad que acosaba a su competidor directo -Colombia-, en el mercado mundial cafetero ${ }^{66}$. Para marzo de 1934, luego de casi un año de haber terminado la confrontación armada directa (por el Acuerdo de Ginebra del 26 de mayo de 1933), se seguía considerando que la amenaza de una eventual guerra de enormes proporciones subsistía, según lo indicó el mismo Cipriano Restrepo a su tío el expresidente:

En lo internacional parece que el Perú tenga pretensiones inauditas y que la guerra puede evitarse únicamente a costa de grandes gastos, de mantener al país en estado de preparación bélica y de armarnos hasta los dientes. En otras palabras, parece que hay necesidad de asustarlos y, a pesar de todo me temo que ni el susto sea suficiente y que al fin y al cabo tengamos que afrontar la situación con valor y decisión ${ }^{67}$.

Desconfianza semejante enunciaron otros corresponsales de Restrepo, pues a juzgar por las apariencias el gobierno peruano conservaba pretensiones bélicas, aunque sin proclamar todavía una decisión definitiva. Pese a ello, y a que en la opinión pública colombiana subsistía una innegable dosis de patriotismo, la excitación cercana al fanatismo manifestada en septiembre de 1932 había aminorado ${ }^{68}$. Con todo, y sobreponiéndose a la inconformidad de una facción del Partido Conservador frente a lo estipulado por el Protocolo de Río de Janeiro (24 de mayo de 1934), una sensata aprobación general prevaleció frente a lo allí pactado ${ }^{69}$. Luis Cano Villegas, dirigente del Partido Liberal y firmante del Protocolo

${ }^{65}$ Carta de Diego Martínez a Carlos E. Restrepo, Cartagena, 13 de septiembre de 1933, A/CER/CR 74B/112:149.

${ }^{66}$ Carta de Cipriano Restrepo Jaramillo a Carlos E. Restrepo, Medellín, 13 de diciembre de 1933, A/CER/CR 75/219:309.

${ }^{67}$ Carta de Cipriano Restrepo Jaramillo a Carlos E. Restrepo, Medellín, 12 de marzo de 1934, A/CER/CR 75/214:300.

${ }^{68}$ Carta de [corresponsal ilegible] a Carlos E. Restrepo, Manizales, 9 de enero de 1934, A/CER/CR 75/115:164.

${ }^{69}$ Álvaro Tirado Mejía, "López Pumarejo: La Revolución en Marcha", en Nueva Historia de Colombia, Vol. I, (Dir.) Álvaro Tirado Mejía (Bogotá: Planeta, 1989), 307-308. 
por Colombia, registró que su país obtuvo finalmente "la defensa de su patrimonio moral, de su bienestar y de su derecho", destacándose como "un pueblo culto y civilizado cuya firma al pie de un pacto antibélico representa algo más que una simple formalidad protocolaria". Según expresó, dicha postura significaba más que cualquier otra $\cos ^{70}$.

\section{Una mirada intelectual a la "embriaguez patriótica".}

El abogado y escritor Fernando González Ochoa (1895-1964), yerno del expresidente Carlos E. Restrepo, profirió algunos pronunciamientos con respecto al Conflicto con el Perú. En la época, González se desempeñaba como cónsul de Colombia en Génova (Italia) y Marsella (Francia). Sus opiniones pueden comprenderse de manera ajustada al contexto, sólo si de antemano se conocen rasgos generales de su irreverente personalidad, que incluso llegó a influenciar posteriores movimientos de la literatura colombiana-como por ejemplo El Nadaísmo (1958-1970)-, caracterizado por una fuerte protesta contra las instituciones tradicionales de la sociedad y la cultura. Inicialmente, González otorgó escasa importancia a la intrusión peruana sobre la ciudad de Leticia. Sin embargo, su aparente inmutabilidad no se redujo a una postura apátrida, sino a la imposibilidad que en principio concedió a una confrontación armada real, directa y de grandes proporciones, conforme lo manifestó a su suegro: "Yo creo que matar peruanos es como matar a los primos y además creo que el amigo Hoover [Herbert Hoover, presidente de los Estados Unidos de América, 1929-1933] no dejará casar esa riña. Los peruanos son muy brutos, pero al fin y al cabo son iguales a nosotros"71.

En opinión de González, las intimidaciones empleadas por el Perú para presionar a Colombia formaban parte de una estratagema, orientada a mantener en el gobierno del país vecino a un dirigente ya desprestigiado, y por tanto ávido de respaldo popular. Pensaba González que en caso de producirse una verdadera guerra, los Estados Unidos se mantendrían

\footnotetext{
${ }^{70}$ Carta de Luis Cano Villegas a Eduardo Santos y al general Agustín Morales Olaya, Río de Janeiro, 9 de mayo de 1934, A/CER/CR 75/181:251.

${ }^{71}$ Carta de Fernando González a Carlos E. Restrepo, Marsella, 24 de septiembre de 1932, A/CER/CR 74A/63:113. Cf. además: Periódico El Tiempo, "Hace 50 años", consultado el 30 de noviembre de 2013. http://news.google.com/newspapers?nid=1706\&dat=19841222\&id=ObsqAAAAIBAJ\&sjid=9WcEAAAAIB AJ\&pg=3508,2006030.
} 
favorables a Colombia, puesto que sus exportaciones eran considerables (en ramos como café, banano, petróleo, etc.), mientras que para la potencia del norte las realizadas por el Perú podían resultar menos apreciables:

Hoover no nos deja pelear: exportan de Colombia 8.000.000 de dólares al mes, de los cuales 6 son yanquis. ¿Cómo dejará que peleemos? Económicamente estamos pegados de Estados Unidos. Apenas Perú, Argentina y Chile exportan juntos a Estados Unidos lo que Colombia [...] Así pues Colombia está segura en sus fronteras. [Por lo que atacar a Colombia] Sería lo mismo que atacar a Estados Unidos. A mí me gusta esta situación de Colombia [...] Así pues, yo no creo en guerras y si la hay no dura tres días porque Estados Unidos, nos ayudará. Con el Perú no tienen sino contrariedades ${ }^{72}$.

Pero, igual que a la inmensa mayoría de colombianos, a González también lo afligió la toma de Leticia. Su postura quedó plasmada en una nota en la que comentó:

Estoy con una neurastenia que todo el mundo me parece que es un peruano [...] Ayer vino un cura dizque chileno a que le revisara el pasaporte. Entró y dijo: Hace 40 años que hago el bien en África educando negros. Quiero ir a Colombia a trabajar en grande por los indios. Eso quiere el Papa etc., etc. Le dije: váyase al Perú. Se fue muy enojado. Fijo que es un peruano ${ }^{73}$.

Poco le atrajo a González que el gobierno colombiano designara a Alfredo Vásquez Cobo, como director de la ofensiva militar orientada a recuperar la región del Amazonas. Militar y político, este general había sido uno de los comandantes conservadores que firmaron el Tratado de Wisconsin al concluir la Guerra civil de los Mil Días (1899-1902). Desde entonces se desempeñó como ministro de distintas carteras, y se desenvolvió fallidamente como candidato a la presidencia en 1926, y en 1930. Para González, el nombramiento de Vásquez como comandante de la campaña militar resultaba infortunado, porque a su juicio tanto él como la comitiva que integró para secundarlo, carecían de las cualidades requeridas para marchar a una guerra, o incluso para soportarla. Para actuar en tales menesteres difícilmente servía colombiano alguno, -expresó González-, pues la idiosincrasia nacional demarcaba comportamientos bastante diferentes: "Colombia es literata y no guerrera", -aseveró-. "Yo nunca he creído en esa guerra; los guerreros buenos son

\footnotetext{
${ }^{72}$ Carta de Fernando González a Carlos E. Restrepo, Marsella, 5 de octubre de 1932, A/CER/CR 74A/112:62. El subrayado figura en el original. Cf. además: Carta de Fernando González a Carlos E. Restrepo, [sin ciudad], 28 de noviembre de 1932, A/CER/CR 74A/56:104.

${ }^{73}$ Carta de Fernando González a Carlos E. Restrepo, Marsella, 26 de enero de 1933, A/CER/CR 74B/53:77.
} 
aquellos negros de Venezuela y los medio paraguayos. Pero nosotros [...] nosotros somos literatos" $" 74$.

Mientras acontecieron los sucesos inherentes al Conflicto, se produjo una turbación sorprendente en la mente de González, nada ajena a la trayectoria misma de su existencia personal. Blasfemo pero honesto, puso en tela de juicio si el regocijo expresado por los colombianos ante el estallido de una supuesta guerra civil en el Perú, resultaba aceptable en términos morales. Cuando el diario parisino Le Journal, del 15 de febrero de 1933, publicó un comentario desmintiendo aquel rumor, subrayó:

\begin{abstract}
Mala noticia esa de que los peruanos no estén fregados. No hay un sólo colombiano que no se vaya a desanimar con esto.

¿Por qué todos deseamos que haya revolución en el Perú?

¿No es inmoral eso? Todo el día he estado preocupado con este problema. Pienso que el principio fundamental es tratar a los demás como queremos que nos traten; no hacer a los otros lo que no queremos que nos hagan. Pero si un tipo va persiguiéndome para matarme o robarme, ¿cómo no me va a ser permitido desear que se caiga y se rompa un pie? A causa de este problema tan difícil, resolví abandonar unos estudios que estaba haciendo acerca de la moral $[\ldots] .^{75}$
\end{abstract}

Un día después, cuando le informaron acerca del inicio de hostilidades, registró que la noticia le había impactado como "una bala en el corazón”. Entonces deseó acompañar a los compatriotas que debían afrontar la campaña militar, y rogó al Creador por el bienestar de Colombia:

Siento cómo se ama la patria [...] quisiera estar allá con nuestros hermanos que sufren $[\ldots]$

¡Caramba a estas horas ya hay muchos colombianos muertos. Pueda ser que su sangre fertilice nuestra tierra y ponga fin a las luchas políticas! Estamos excitados $[\ldots]$ Ahora nuestro deber es luchar.

Yo estoy resuelto a todo; a aceptar con alegría el llamamiento que no tardaré y a desempeñar mi parte en el gran deber.

¡Cómo embriaga la sangre que sube a la cabeza cuando ofenden a la patria! Primera vez que siento el patriotismo como una embriaguez ¡qué raro es el patriotismo! ¡Al diablo la moral y la filosofía! Hoy no existe para mí sino el amor de Patria y ruego a Dios por el castigo de ese bizco Sánchez Cerro.

¡Viva Colombia! Por encima de todo, de filosofía, de moral y de afectos, ¡viva Colombia! ${ }^{76}$

\footnotetext{
${ }^{74}$ Carta de Fernando González a Carlos E. Restrepo, Marsella, $1^{\circ}$ de febrero de 1933, A/CER/CR 74B/52:76.

${ }^{75}$ Carta de Fernando González a Carlos E. Restrepo, Marsella, 15 de febrero de 1933, A/CER/CR 74B/48: 67. El subrayado figura en el original.

${ }^{76}$ Carta de Fernando González a Carlos E. Restrepo, [sin ciudad], 16 de febrero de 1933, A/CER/CR 74B/49:69.
} 
Sin embargo, tres semanas más tarde, González anotó con singular tono que para entonces ya se le había pasado el patriotismo, porque ni embriagado podía entusiasmarse con Vásquez Cobo al mando de la ofensiva nacional ${ }^{77}$. Tan pronto esta finalizó con victoria para Colombia (gracias a la toma de Güepí en el alto Putumayo, el 26 de marzo de 1933, evento que afirmó la posición argumental del país ante la Liga de la Naciones) ${ }^{78}$, el sosiego retornó a González, llevándolo a afirmar que en último término toda la confrontación quedó circunscrita a la publicación de "cien folletos compuestos de títulos", en alusión a la dilatada producción de editoriales y comunicados de prensa que auguraron una guerra de grandes proporciones, errando finalmente en dicha predicción, ya que nunca alcanzó tales dimensiones. A González, que percibía su juicio personal como signado por un ánimo crítico permanente, jamás lograron persuadirlo -conforme dijo- los augurios difundidos por la prensa, pareciéndole más bien voces huecas, siempre sordas, sin sentido ${ }^{79}$.

\section{Un diplomático genuino.}

La misión asignada a Eduardo Santos para enfrentar el Conflicto, canalizó ágilmente el sentimiento patriótico. En efecto, él no fue un mero espectador, sino quien en buena medida estableció la estrategia para solucionar la crisis. Ejerció como comisionado en Europa, y en todo momento señaló que pese a los obstáculos, podía concertarse la exaltación patriótica con la efectiva acción diplomática. Solventó con su propio peculio los gastos de representación y oficina ante la Sociedad de las Naciones, en Ginebra, Suiza. Esta labor se prolongó hasta el 26 de mayo de 1933, cuando se rubricó el denominado Acuerdo de Ginebra $^{80}$, dictamen que determinó la recuperación para Colombia de las prerrogativas contempladas por el Tratado Salomón-Lozano de 1922 ${ }^{81}$. Anticipándose a las divisiones internas que de seguro sobrevendrían con las próximas contiendas electorales, Santos se dio a la tarea de intercambiar ideas con otros conocedores del devenir político nacional. Con el ánimo de evitar discrepancias en el sensible entorno político colombiano, propuso posponer todo debate electoral hasta que se cumpliera al menos medio año de la firma de un acuerdo

\footnotetext{
${ }_{77}^{77}$ Carta de Fernando González a Carlos E. Restrepo, Marsella, 4 de marzo de 1933, A/CER/CR 74B/45:64.

78 Álvaro Valencia Tovar, "Historia militar contemporánea", 323.

${ }^{79}$ Carta de Fernando González a Carlos E. Restrepo, Marsella, 21 de junio de 1933, A/CER/CR 74B/28:38.

${ }^{80}$ Raimundo Rivas, Historia Diplomática de Colombia (1810-1934) (Bogotá: Imprenta Nacional, 1961$), 726$.

${ }^{81}$ Telegrama de Eduardo Santos a Carlos E. Restrepo, París, [sin fecha], A/CER/CR 74B/250:349.
} 
de paz con el Perú. De esa forma buscó fortalecer la unidad nacional, resguardándola de la cotidiana pero lesiva práctica de promover "deportes partidistas" 82 . Lo mismo que cualquier otro ciudadano, advirtió en la invasión peruana un elemento concitador de patriotismo y unidad, favorable a la superación de los tradicionales desacuerdos políticos. En ese sentido, escribió a Restrepo desde París:

Ya estará Ud. recibiendo periódicos y verá que el movimiento patriótico en Colombia ha pasado todos los límites y logró en dos horas acabar con todas las diferencias políticas; eso sacaremos de bueno de esta aventura, y a veces me provoca que dure para que al menos [ponga fin al] [...] repugnante espectáculo de las discordias interiores [...] Se diría que los hombres necesitan ante todo un enemigo para unirse como partido o como nación [...] Resulta que con todos estos sucesos me he descubierto un patriotismo lírico y sentimental con alma de mitinguero y ganas de andar con un chopo Putumayo abajo.

Creo que se han despertado todos mis antecesores santandereanos y lo primero que hicieron fue devorar al diplomático que Ud. y Olaya inventaron el 7 de agosto [de $1930]^{83}$.

Santos avistó lúcidamente la polémica que amenazaba con desaguar en un conflicto absurdo pero ineludible. Al referirse al costo de algunas piezas de artillería indispensables para dotar al ejército, avaluadas en 350.000 dólares, anotó que con la mitad de ese dinero se podría crear un promisorio Instituto del Radio, encargado de combatir infinidad de dolencias en Colombia y de propiciar "una base indispensable de investigación científica sobre las enfermedades tropicales ${ }^{84}$. De hecho, por aquellos años el exministro de Instrucción Pública José Vicente Huertas junto con algunos miembros del Congreso de la República, venían impulsando esa iniciativa, que finalmente fructificó con la fundación del Instituto Nacional de Radium como primer centro de su clase en América Latina, el 20 de julio de $1934^{85}$. Con todo, atender la situación creada por el Perú, incluso si ello conllevaba costos impensados, resultaba para Santos impostergable:

No podemos vacilar [-afirmó-] porque la vida es absurda y porque los pueblos tienen en ciertas horas la obligación de hacer cosas insensatas porque la prudencia y la cordura les llevarían derecho a la muerte moral. Si el Perú se quedara con

\footnotetext{
${ }^{82}$ Carta de Eduardo Santos a Carlos E. Restrepo, París, 2 de octubre de 1932, A/CER/CR 74A/212:365.

${ }^{83}$ Carta de Eduardo Santos a Carlos E. Restrepo, París, 4 de octubre de 1932, A/CER/CR 74A/ 214:368.

${ }^{84}$ Carta de Eduardo Santos a Carlos E. Restrepo, París, 9 de diciembre de 1932, A/CER/CR 74A/196:337.

85 Instituto Nacional de Cancerología, "Reseña histórica", consultado el 11 de diciembre de 2016. http://www.cancer.gov.co/rese\%C3\%B1a-hist\%C3\%B3rica-inc.
} 
Leticia, todos los institutos del Radio que fundáramos en Colombia serían poco para curar el cáncer que devoraría el alma colombiana ${ }^{86}$.

Como hábil diplomático, consideraba que no debían tomarse determinaciones distintas de las ya estipuladas por el Tratado Salomón-Lozano. De otra parte, la invasión peruana sólo dejaba abierta para Colombia la reconquista obligada del territorio. En diciembre de 1932, cuando las cancillerías de Francia e Inglaterra avalaron esa opinión, y luego de estudiar detenidamente el diagnóstico del expresidente Restrepo, Santos sugirió darle un giro transcendental al asunto, dejando de enfocarlo frente al mundo como un problema interno. Entonces planteó darle un talante resueltamente internacional, toda vez que creaba circunstancias que no se podían "esquivar sin quedar en la más difícil de las posturas", puesto que tarde o temprano podrían "culminar en una guerra", situación que era indispensable tratar mediante "una franca ofensiva diplomática de caracteres muy enérgicos", para "jugar con todas las cartas sobre la mesa" ${ }^{\text {" }}$. Esta propuesta fue escuchada en las altas esferas oficiales sin demoras, generando un cambio transcendental orientado al rescate del Amazonas. Entre tanto, Santos escuchó atentamente los reclamos del Perú, y midió sus pros y sus contras, pero sosteniendo un no rotundo a las pretensiones del país vecino, pues consideraba que "estudiar no es convenir ni negociar equivale a transigir". Entonces apareció una ingrata indisposición partidista: los periódicos liberales culparon al presidente Olaya Herrera de exponer a Colombia a una guerra civil, factible según dijeron por la escogencia del general conservador Vásquez Cobo como comandante de las operaciones militares en la frontera. Por su parte, el dirigente Laureano Gómez responsabilizó al ejecutivo de causar la reciente muerte de algunos militantes del Partido Conservador. Ambas críticas hicieron que Santos lamentara la escasa cohesión interna: "no veo muy seguro el frente único en Colombia" ${ }^{98}$. Pero a pesar de ello, restó importancia a los detractores del gobierno, y se concentró en llevar a efecto de manera silenciosa, la labor que le había sido encomendada ${ }^{89}$.

La postura diplomática fue en buena medida diseñada por Santos, quien en notificación dirigida al secretario de la Sociedad de las Naciones, Sir Eric Drummond,

\footnotetext{
${ }^{86}$ Carta de Eduardo Santos a Carlos E. Restrepo, París, 9 de diciembre de 1932, A/CER/CR 74A/196:337.

${ }^{87}$ Carta de Eduardo Santos a Carlos E. Restrepo, París, 18 de diciembre de 1932, A/CER/CR 74A/193:329.

${ }^{88}$ Carta de Eduardo Santos a Carlos E. Restrepo, París, 24 de diciembre de 1932, A/CER/CR 74A/191:325.

${ }^{89}$ Carta de Eduardo Santos a Carlos E. Restrepo, París, 14 de enero de 1933, A/CER/CR 74B/244:341.
} 
desmintió que Colombia pretendiera convertirse en una “potencia amazónica”. Según aclaró, el país únicamente estaba interesado en preservar los derechos históricos esenciales sobre su territorio, los cuales le habían sido otorgados por la naturaleza y por los tratados limítrofes vigentes. Añadió que si se violaban dichos convenios entre Estados, se daría una "formidable novedad en el derecho internacional", porque "con esa tesis no quedaría en el mundo frontera tranquila ni pueblo seguro". Expresó la mejor disposición en procura del restablecimiento de la paz y la cooperación franca entre Estados y pueblos, y solicitó la ayuda de los países civilizados adscritos a la Sociedad de las Naciones, de quienes esperaba un riguroso apego al derecho ${ }^{90}$. Pese a su ingente labor diplomática, Santos recibió duras críticas en Colombia: quienes azuzaban discrepancias en la política interna lo acusaron de ser un propulsor de beneficios personales o "pescador de canonjías", que no había temido validar el "engendro de Ginebra". Afortunadamente para él, cuando el dirigente liberal y próximo presidente de la República Alfonso López Pumarejo “izó su gallardete en lo alto de esta negociación y le puso su firma y sello" 91 , fueron escasos los miembros del Partido Liberal que en lo sucesivo reprobaron su actuación. Puede decirse que por el contrario, más bien optaron por celebrar su actividad acuciosa.

Públicamente también se expresaron pensamientos incautos en las lides diplomáticas, como por ejemplo los formulados por el poeta Guillermo Valencia, quien antes de actuar como delegado por Colombia en la firma del Protocolo de Río, argumentó, de manera equivocada, que la presencia de una delegación de la Sociedad de las Naciones resultaba deseable en Leticia, puesto que entre sus obligaciones principales aquella Sociedad observaba la defensa de las minorías. Según afirmó Santos, esa aseveración falseaba el espíritu de un eventual acuerdo que devolviera las áreas ocupadas, como también la "Teoría de las minorías" defendida por la entidad aludida, pues conforme aclaró, en el territorio pretendido por el Perú no habitaban minorías raciales, ni religiosas, ni económicas. Para el mes de julio de 1933 el avance diplomático era más que significativo. Sin embargo, los peruanos continuaban apegados a dirimir el Conflicto mediante las armas, lo que incentivó en Santos -según lo manifestó a Restrepo-, la conservación de una postura “de

\footnotetext{
${ }^{90}$ Carta de Eduardo Santos a Sir Eric Drummond, Ginebra, 31 de enero de 1933, A/CER/CR 74B/236:321.

${ }^{91}$ Carta de Eduardo Santos a Carlos E. Restrepo, Madrid, 27 de junio de 1933, A/CER/CR 74B/221:01.
} 
inquebrantable energía y firmeza", así como la decisión “de no mostrar el menor síntoma de debilidad; de no descuidar nuestra preparación militar y de prepararnos para cualquier emergencia" 92 . Terminando octubre de 1933, cuando ya habían comenzado las conversaciones en Río de Janeiro (que se extendieron hasta febrero 23 del año siguiente), los cautos métodos de Santos comenzaban a rendir frutos. En ese instante decisivo, el minucioso examen escrito por Santos "Memorándum sobre la prórroga del mandato de La Liga en Leticia”, exhibió caviladas observaciones orientadas a demostrar lo inconveniente que para Colombia era la continuación del dominio de la Comisión internacional que administraba Leticia $^{93}$. Esa postura fue confirmada mediante nota oficial remitida por Santos al secretario general de la Sociedad de las Naciones. Allí sostuvo que Colombia no perseguía nada distinto de la simple preservación de su soberanía, y del ejercicio "de sus derechos soberanos y de [los] acuerdos amistosos que permitían la convivencia cordial y la colaboración fecunda de pueblos afines a quienes todo aconseja una sincera cooperación"94. Recuérdese que lo acordado otorgaba a la citada comisión un dominio administrativo transitorio sobre Leticia, después de lo cual Colombia recibió la ciudad de manera definitiva el 19 de junio de $1934^{95}$. El Protocolo se había firmado el 24 de mayo anterior.

Santos siempre abogó por una postura reflexiva y digna. Ello a pesar de que como colombiano, sentía -sobre todo durante los episodios iniciales del Conflicto- cierta exaltación, que sin embargo supo manejar con pausa y justeza en aras de una aceptación pública racional, afín a los métodos exigidos por la diplomacia. ${ }^{96}$ Junto con su lucidez, la ofrecida por otros conocedores del terreno diplomático evidenció concordancia. De consuno, conjugaron exaltación patriótica y visión meditada. Partícipes en ello fueron el educador, abogado y escritor Agustín Nieto Caballero; y claro está, el expresidente Carlos E. Restrepo. Compañeros de causa, identificaron más ventajas que desventajas en una propuesta inicial formulada por el canciller brasilero Afranio de Mello Franco, que se convertiría en la

\footnotetext{
${ }^{92}$ Carta de Eduardo Santos a Carlos E. Restrepo, París, 24 de julio de 1933, A/CER/CR 74B/219:297.

${ }_{93}$ Memorándum sobre la prórroga del mandato de La Liga en Leticia, escrito por Eduardo Santos, Río de Janeiro, 31 de enero de 1934, A/CER/CR 75/235:352.

${ }^{94}$ Carta de Eduardo Santos al secretario general de la Sociedad de las Naciones, Ginebra, 18 de marzo de 1934 , A/CER/CR 75/229:324.

${ }^{95}$ República de Colombia, Protocolo de Río de Janeiro. Texto del protocolo. Proyecto de Ley y exposición de motivos (Bogotá: Imprenta Nacional, 1934), 17-20.

${ }^{96}$ Carta de Eduardo Santos al secretario general de la Sociedad de las Naciones, Ginebra, 4 de abril de 1934, A/CER/CR 75/231:355.
} 
columna vertebral del Protocolo de Río. Allí los derechos defendidos por Colombia otorgaban respeto irrestricto a los acuerdos pactados, a la soberanía nacional y al restablecimiento de las autoridades. Por todo, tanto Santos, como Restrepo y Nieto Caballero, identificaron en la pauta sugerida por el canciller brasilero opciones, que si bien podrían acarrear obstáculos, resultaban preferibles a otras salidas, puesto que la propuesta evitaba, conforme lo manifestaron-, la ruptura del diálogo y la renovación del Conflicto. Por el contrario, abría "caminos de paz y de acuerdo", que Colombia se encontraba "en la obligación de ensayar". ${ }^{97}$ Este raciocinio influenció al presidente Olaya Herrera, quien finalmente aceptó la firma de la paz en Río de Janeiro, cerrando un capítulo que enmarcó un sinnúmero de contrariedades -hipotéticas o no-, pero siempre acuciantes para Colombia durante más de un siglo.

\section{La percepción de un estadista.}

La vasta información que reposa en el Archivo de Carlos E. Restrepo, refleja una imagen fehaciente de la vida política colombiana hasta mediados de los años 1930. El renombre del exmandatario testimonia sin duda su figuración y peso específico durante la época. Actuando como presidente de la República, Restrepo había afrontado ya la política limítrofe del Perú, pues, como se ha señalado en páginas previas, hubo de lidiar con el acontecimiento de La Pedrera (10 al 12 de julio de 1911). No resulta extraño, por tanto, que a partir de septiembre de 1932 cuando sobrevino el Conflicto colombo-peruano, su conocimiento y experiencia concitaran la atención de la administración en ejercicio, la del presidente Olaya Herrera, máxime cuando recientemente (entre agosto de 1930 y julio de 1931), Restrepo se había desempeñado en el gabinete ministerial a cargo de la cartera del Interior ${ }^{98}$. Luego pasó a oficiar como ministro plenipotenciario de Colombia ante la Santa Sede. El 5 de septiembre 1932, apenas cuatro días después de la toma peruana de Leticia, se comunicó con su amigo el librero y poeta Antonio José Cano, encomiando la necesidad de

\footnotetext{
${ }^{97}$ Carta de Eduardo Santos, Carlos E. Restrepo y Agustín Nieto a Enrique Olaya Herrera, Ginebra, 16 de mayo de 1934, A/CER/CR 75/200:282.

98 Andrés González Díaz, "Ministros bajo la presidencia de Enrique Olaya Herrera”, Ministros del siglo XX. Primera parte, consultado el 14 de diciembre de 2016. http://www.banrepcultural.org/blaavirtual/todaslasartes/obrames/ministros/ministros13.htm.
} 
aceptar cualquier deber y/o sacrificio que la situación exigiera ${ }^{99}$. Enfatizó que al país se le debía servir de manera incondicional ${ }^{100}$. Sensiblemente afectado, agregó que el derecho colombiano era "más luminoso que el sol del último Inca"101, y que a su parecer Colombia entera se encontraba obligada a batallar, hasta desaparecer si fuere preciso, tanto la nación como sus hombres, ya que ese era el "único medio de sustituir la guerra por la paz, la barbarie por la civilización"102. La dificultad económica que por entonces experimentaba el país repercusión de la Gran Crisis Mundial de 1929, aunada a las constantes disputas entre partidos-, le hicieron observar que tan adverso escenario asemejaba la situación colombiana con la de "el Job de las naciones", y que manifestara desconfianza sobre la acción unificadora de las ardientes expresiones patrióticas - a veces desaforadas- generadas por la invasión peruana. Desbordes de entusiasmo de esa naturaleza poco le agradaban a Restrepo, por lo que en tono mesurado conceptuaba que el país no podía permitirse caminar en falso ni atacar equivocadamente, sino sólo después de tener total certeza de poder propinar golpes avasallantes, dejándose guiar por una emoción cauta e irreductible ${ }^{103}$.

En los primeros días de octubre de 1932, la Cancillería del Perú extendió un comunicado a la de Colombia, solicitando la mediación o el arreglo directo de "las diferencias" existentes entre los dos Estados. Restrepo manifestó entonces a Eduardo Santos, que se hacía necesario recurrir a una verdadera humildad franciscana para no reventar de furia, pues el presidente peruano Sánchez Cerro parecía no tratar con una nación vecina, sino más bien "con niños o con salvajes", agudizando su perfidia hasta los "extremos del cinismo". Afortunadamente, a juicio de Restrepo, la acertada respuesta del gobierno colombiano "le retorció muy bien los argumentos y el pescuezo y dejó las cosas en su punto"104. Esta certeza fue confirmada en nota dirigida por Restrepo al ministro de Relaciones Exteriores, Roberto Urdaneta Arbeláez: "la actitud del gobierno y del pueblo colombiano no puede ser más correcta. En la defensa de nuestros derechos debemos ir hasta

\footnotetext{
${ }^{99}$ Carta de Carlos E. Restrepo a A. J. Cano, Roma, 6 de septiembre de 1932, A/CER/CE 74A/22:26.

100 Carta de Carlos E. Restrepo a Enrique Olaya Herrera, Roma, 28 de septiembre de 1932, A/CER/CE 74A/155:252.

${ }^{101}$ Carta de Carlos E. Restrepo a Jaime Holguín, Roma, 6 de octubre de 1932, A/CER/CE 74A/94:155.

102 Carta de Carlos E. Restrepo a Ricardo Hinestroza Daza, Roma, 6 de octubre de 1932, A/CER/CE 74A/92:152.

${ }^{103}$ Carta de Carlos E. Restrepo a Eduardo Santos, Roma, 14 de octubre de 1932, A/CER/CE 74A/213:366.

${ }^{104}$ Carta de Carlos E. Restrepo a Eduardo Santos, Roma, 7 de octubre de 1932, A/CER/CE 74A/217:372.
} 
el fin y si para ello es preciso sostener una guerra más devastadora que la de nuestra Independencia, la sostendremos" ${ }^{\text {105 }}$. Toda consideración sobre el momento se reducía entonces, según Restrepo, a lo esencial: "Colombia no tendría razón de ser como nación [dijo a su amigo el ingeniero y dirigente liberal Alejando López-] si los vecinos se creyeran con la facultad de hecho o de derecho, de apoderarse de nuestro territorio, o somos capaces de defendernos o desaparecemos"106. El expresidente creía que la presión moral ejercida por una veeduría internacional sobre el gobierno peruano sería ineficaz, y que aquello que Colombia no llevara a efecto por sus propios medios no sería realizado tampoco por ningún otro país. En última instancia el escenario hacía ineludible aceptar una guerra, que para entonces era "inevitable y necesaria". Carlos E. Restrepo argumentaba que de no tomar tal resolución, otros países vecinos como Venezuela, Ecuador o Panamá, también podrían ocupar el territorio colombiano, pasando por alto tratados internacionales y legalizando su acción sobre el precedente de la audacia peruana y la incapacidad manifiesta de Colombia ${ }^{107}$. Una guerra de grandes magnitudes arruinaría de seguro a ambos países, pero a su juicio, Colombia sería capaz de renacer de las cenizas ${ }^{108}$. El amplio respaldo político y popular que rodeó al gobierno colombiano durante los primeros meses de la confrontación, aparentemente protegido de los ardores partidistas en ese momento-, así permitía pronosticarlo.

Residente en Roma como embajador colombiano ante la Santa Sede, Restrepo nunca dejó de experimentar una tensión intranquila. La imposibilidad de hallarse en Colombia, le produjo abatimiento y desvelos ${ }^{109}$. Cuando los delegados del Perú ante la Sociedad de las Naciones exigieron la revisión del Tratado Salomón-Lozano firmado en 1922, Restrepo expresó montando en cólera:

Si desde los tiempos de la emancipación no hubiera agotado el Perú las palabras y los caminos falsos, torticeros, sinuosos, arteros, pérfidos $\& \&$, podría decirse que

\footnotetext{
${ }^{105}$ Carta de Carlos E. Restrepo a Roberto Urdaneta Arbeláez, Roma, 10 de octubre de 1932, A/CER/CE 74A/245:409.

${ }^{106}$ Carta de Carlos E. Restrepo a Alejandro López, Roma, 27 de octubre de 1932, A/CER/CE 74A/114:184.

107 Carta de Carlos E. Restrepo a Saturnino Restrepo, Roma, 10 de noviembre de 1932, A/CER/CE 74A/182:311.

${ }^{108}$ Carta de Carlos E. Restrepo a Eustasio Camargo, Roma, 16 de noviembre de 1932, A/CER/CE 74A/14:14.

109 Carta de Carlos E. Restrepo a Roberto Urdaneta Arbeláez, Roma, 12 de enero de 1933, A/CER/CE 74A/240:400.
} 
los acendra y cimienta en ese documento canalla que desconcierta y anula toda noción de justicia, de sentido común, de delicadeza y de pudor. Artificios como ese no pueden destruirse sino a balazos, que es sin duda lo que ha resuelto nuestro gobierno cuando mandó seguir la expedición [militar de recuperación] hacia Leticia. La suerte está echada y hay que creer que el éxito corresponderá a la magnitud de nuestra justicia ${ }^{110}$.

En aquel instante cualquier conversación con los reticentes representantes peruanos se evidenciaba improductiva ${ }^{111}$. Irritado, Restrepo le manifestó al presidente Olaya Herrera una frase lapidaria, citando una expresión proferida en el siglo XIX por el general José María Córdoba, alusiva al comportamiento de los gobiernos peruanos frente a Colombia: "Con ellos, como lo afirmaba el paisano general Córdoba, no se puede hablar ni hacer tratados sino a balazos". En la misma carta añadió:

Imaginará Ud. cómo estamos en estos mismos minutos, en que se debe estar desarrollando el primer choque; de hacer fuerza estamos reventando y lo que soy yo ni como ni duermo. Me hago la ilusión de un triunfo y me imagino que él circunscribiría nuestra acción bélica a la región del Amazonas y que duraría poco tiempo, mientras Loreto se agota y se da campo a que derriben a Sánchez Cerro. Si la suerte nos fuera adversa -Dios no lo ha de permitir- quiere decir que allí empezaría la verdadera guerra. O mucho me equivoco, o Ud. puede pedirle al país todo género de sacrificios, hasta agotarnos, hasta desaparecer, y estoy seguro de que Colombia responderá. Si no, quiere decir que somos indignos del gobierno que nos hemos dado, de la República y de nuestra emancipación ${ }^{112}$.

Diversas opiniones rondaban entonces: algunas pidiendo pacifismo, otras esparciendo claro derrotismo, y algunas más aventurando -incluso- un declarado anti-patriotismo. Pero a pesar de todo, en concepto de Restrepo todavía resultaba posible ahogar esas voces equívocas "sin piedad ni misericordia". Y frente a una situación extrema era necesario actuar así, puesto que en el entorno político interno se aproximaban las elecciones de 1933, atrayendo el consabido resquemor partidista, poniendo en entredicho la unidad nacional y la continuidad del manejo exterior trazado por la administración Olaya, única capaz en ese instante -en opinión de Restrepo- de salvar a un pueblo nervioso que, diferenciándose del británico - por ejemplo-, no sabría perder múltiples batallas conservando la calma para vencer en la última ${ }^{113}$. Luego del triunfo militar colombiano en Tarapacá, Restrepo comunicó

${ }^{110}$ Carta de Carlos E. Restrepo a Eduardo Santos, Roma, 20 de enero de 1933, A/CER/CE 74B/243:340.

${ }^{111}$ Sandra Milena Hernández Rodríguez, "Análisis de las estrategias de actores nacionales e internacionales en la firma de los acuerdos diplomáticos suscritos entre Perú y Colombia en 1934...”, 22-23,29-32.

${ }^{112}$ Carta de Carlos E. Restrepo a Enrique Olaya Herrera, Roma, 26 de enero de 1933, A/CER/CE 74A/146: 228.

${ }^{113}$ Carta de Carlos E. Restrepo a Roberto Urdaneta Arbeláez, Roma, 17 de noviembre de 1932, A/CER/CE 74B/244:406. 
a su amigo, el político de la ciudad de Medellín Francisco Escobar: "Lo que es evidente es que la guerra se ha venido encima, pero tengo la firme persuasión que será corta y de poca duración. El sargentón de Sánchez Cerro está vacilante y puede caer de un momento a otro"114. Para marzo de 1933, mientras Colombia seguía fortaleciendo su diplomacia y su ofensiva militar, la postura peruana perdía fuerza, tanto dentro del propio Perú como en el orbe entero. Frente a las dificultades que Colombia avizoraba, el expresidente consideraba que no podía permitirse ni soportarse una derrota más. El pragmatismo que siempre había caracterizado a sus razonamientos, brilló en ese sentido: como le expresó al político y líder regional antioqueño Jorge Gartner ${ }^{115}$, toda dificultad debía solucionarse sin aplazamientos, lo que implicaba la defensa del territorio por sobre cualquier otro propósito, ya que de no hacerlo la nación podría ser borrada "del mapa"116. Esa percepción le concedía un hálito tajante y combativo. Pero su postura nunca se redujo al irracionalismo ni al apresuramiento. De un lado, apeló a un indudable sentimiento patriótico: "No es imposible que tengamos que oír al Perú y admitir que otros intervengan en nuestro hogar; pero eso será cuando ya no haya en él más que cenizas y tengamos que presentarnos con la cara de los vencidos, pero vencidos en lucha desesperada. Implacable. Dios no lo permitirá [...]"117. De otra parte, acudió a una reflexión crítica sobre la guerra, resaltando que minaba las economías de dos países, que en vez de invertir en la compra de costosos pertrechos - enriqueciendo a las potencias que los fabricaban y vendían-, debían enfocar sus esfuerzos en atender la obligación ética determinada por necesidades cotidianas elementales, como la construcción de vías públicas o de escuelas ${ }^{118}$. Tal postura no reñía con una salida pacífica, que cuando fue propuesta de manera concreta recibió el apoyo del expresidente, quien señaló que si evitar la confrontación armada fue imposible en un primer momento, un arreglo pacífico podría sobrevenir eventualmente, en el caso de que en Perú fuera depuesto Sánchez Cerro, pues según sabía, recibía duras críticas de su propia gente ${ }^{119}$.

\footnotetext{
${ }^{114}$ Carta de Carlos E. Restrepo a Francisco Escobar, Roma, 21 de febrero de 1933, A/CER/CE 75/107:153.

115 María Cristina Arango de Tobón, Publicaciones periódicas en Antioquia 1814-1960: del chibalete a la rotativa (Medellín: Universidad EAFIT - Fondo Editorial Universidad EAFIT, 2006), 264.

${ }^{116}$ Carta de Carlos E. Restrepo a Jorge Gartner, Roma, 26 de noviembre de 1932, A/CER/CE 74A/59:108.

117 Carta de Carlos E. Restrepo a Eduardo Santos, Roma, 22 de diciembre de 1932, A/CER/CE 74A/194:331.

${ }^{118}$ Carta de Carlos E. Restrepo a Eduardo Santos, Roma, 14 de diciembre de 1932, A/CER/CE 74A/197:338.

${ }^{119}$ Carta de Carlos E. Restrepo a Eduardo Santos, Roma, 2 de diciembre de 1932, A/CER/CE 74A/200:346.
} 
Las disputas entre facciones políticas colombianas eran, en concepto de Restrepo, más nefastas para la unidad nacional que la misma Armada peruana, por lo que sus promotores merecían "cinco balazos por la espalda"120. El expresidente no se explicaba cómo mientras los peruanos cerraban filas en torno a "un sargentón sin pena y sin prestigio", para abril de 1933 los partidos políticos colombianos se mostraban incapaces de expresar a la comunidad internacional alguna cohesión interna ${ }^{121}$. Los críticos del gobierno, (y básicamente una facción del Partido Conservador liderada por Laureano Gómez y por Gonzalo Restrepo Jaramillo, este último sobrino suyo) lo indignaban, al punto de hacerlo considerar que sería útil enrolarlos en el ejército y enviarlos a combatir en la jungla, puesto que experimentando en carne propia los costos de la defensa, comprobarían -lejos de las cómodas curules parlamentarias y de la prensa-, "que una cosa es representar sobre el escenario y otra silbar desde el gallinero" ${ }^{\text {22 }}$. El 15 de mayo de 1933 los delegados colombianos ante la Sociedad de las Naciones quedaron atónitos, cuando el candidato a la presidencia de Colombia, el liberal Alfonso López Pumarejo, viajó a Lima contando con la aquiescencia del presidente Olaya Herrera -pero bajo su absoluta responsabilidad-. López buscó y consiguió dialogar con Óscar Benavides, el sucesor de Sánchez Cerro en la presidencia del Perú, “con quien tenía una antigua relación producto de actuaciones conjuntas en la diplomacia"123. Este inesperado encuentro suspendió la jurisdicción de lo hasta entonces avanzado por Santos en la Sociedad de las Naciones, y generó gran sorpresa en Restrepo, quien, como la mayoría de sus compatriotas -e incluso de los negociadores peruanos-, desconocía las gestiones de López ${ }^{124}$. Al conocer el adelanto de esas diligencias, Restrepo anotó en términos prudentes: "me parece lo mejor a lo que podía aspirarse en las presentes condiciones y si acaso no llega a ser definitivo - con los peruanos no hay nada definitivonos deja respirar y prepararnos mejor" ${ }^{\prime 25}$. Cuando finales de junio de 1933 la negociación en Río de Janeiro se evidenció estable, Restrepo manifestó al presidente Olaya Herrera que el Acuerdo previo firmado en Ginebra - cuyos términos estudió detenidamente--, ofrecía un

\footnotetext{
${ }^{120}$ Carta de Carlos E. Restrepo a Jaime Holguín, Roma, 18 de abril de 1933, A/CER/CE 74B/80:111.

${ }^{121}$ Carta de Carlos E. Restrepo a María Vélez de Orillac, Roma, 21 de abril de 1933, A/CER/CE 74B/282:398.

122 Carta de Carlos E. Restrepo a Roberto Urdaneta Arbeláez, Roma, 9 de mayo de 1933, A/CER/CE 74B/276:389.

123 Álvaro Tirado Mejía, “López Pumarejo: La Revolución en Marcha”, 331.

${ }^{124}$ Carta de Carlos E. Restrepo a Jorge Gartner, Roma, 17 de mayo de 1933, A/CER/CE 74B/39:57.

${ }^{125}$ Carta de Carlos E. Restrepo a Tulio A. Forero, Roma, 7 de junio de 1933, A/CER/CE 74B/7:8.
} 
escenario promisorio, porque otorgaba "honra y gloria" a Colombia, además de "ventajosas posiciones" ante futuras acciones de los peruanos ${ }^{126}$. Posteriormente, Restrepo le comunicó a Urdaneta Arbeláez su deseo de que el Protocolo permaneciera vigente "hasta la consumación de los siglos", agradeciéndole de paso a Urdaneta su destacada actuación. Le aconsejó, así mismo, obviar los ataques encabezados por los políticos opuestos a la firma: “deje que los canes sigan ladrando y pidiendo sin peligro para ellos, que sigan la carnicería y la desolación en las selvas amazónicas"127. Esto en referencia a las agresiones que Laureano Gómez empleó para desautorizar el pacto conseguido, postura que el expresidente consideraba no sólo infortunada sino además mezquina ${ }^{128}$, pues con su firma las motivaciones que desencadenaron la guerra se resolvieron oportunamente, dando bienestar y sosiego a infinidad de hogares colombianos:

Lo de Leticia dejémoslo al tiempo. Está en nuestro poder y el quitárnosla será difícil. Lo que no alcanzo a comprender es la lógica de nuestras pasiones políticas: se atacó al gobierno porque sostenía la guerra, y ahora se le ataca porque hace la paz. Antes la guerra fue una ficción, un truco; ahora la paz es una deshonra. Ante ese criterio es inútil discutir sobre la verdad y la justicia ${ }^{129}$.

En suma, el avance en Río de Janeiro fue bien visto por Restrepo, quien observó que, sólo a partir de ese momento los peruanos contaron con la oportunidad de salir del fango en el que se habían atrincherado, a la vez que simultáneamente los colombianos tuvieron ocasión de adoptar posturas ventajosas, ahorrándose enormes pérdidas de vidas. Para Restrepo el mejor camino en ese momento fue el del diálogo ${ }^{130}$, recibiendo el triunfo moral de Colombia con regocijo. Sin embargo, hubiera preferido una victoria militar que complementara el triunfo diplomático ${ }^{131}$, porque conocedor del accionar histórico del Perú, desconfiaba del acatamiento de la decisión jurídica ${ }^{132}$. Los peruanos, según concluyó en carta a su amigo Marco Tobón Mejía, “no tienen que ver nada con moral y hay que abrumarlos con razones

\footnotetext{
${ }^{126}$ Carta de Carlos E. Restrepo a Enrique Olaya Herrera, Roma, 20 de junio de 1933, A/CER/CE 74B/155:209.

${ }^{127}$ Carta de Carlos E. Restrepo a Roberto Urdaneta Arbeláez, Roma, 23 de junio de 1933, A/CER/CE 74B/271:381.

${ }^{128}$ Carta de Carlos E. Restrepo a Eduardo Santos, Roma, 27 de junio de 1933, A/CER/CE 74B/222:302. Cf. además: Abelardo Forero Benavides, "El 13 de junio de 1953. Un día con 3 presidentes: Urdaneta, Gómez y Rojas Pinilla", Credencial Historia, no. 6 (junio de 1990): 4-5.

${ }^{129}$ Carta de Carlos E. Restrepo a Francisco Escobar, Roma, 2 de agosto de 1933, A/CER/CE 75/88:119.

${ }^{130}$ Carta de Carlos E. Restrepo a Francisco Escobar, Roma, 3 de enero de 1933, A/CER/CE 74A/26:37.

131 Telegrama de Carlos E. Restrepo a Eduardo Santos, Roma, 26 de enero de 1933, A/CER/CE 74B/239:332.

${ }^{132}$ Carta de Carlos E. Restrepo a Florentino Goenaga, Roma, 27 de enero de 1933, A/CER/CE 74A/48:94.
} 
aplastantes"133. Por la misma razón escribió a Eduardo Santos: "Dígame hechos, dígame que triunfamos, literatura nos sobra" ${ }^{134}$. No obstante elogió la labor efectuada por Santos, a quien auguró éxitos - pues sus acciones, consideraba, comportaban la posibilidad futura de que Santos llegara a ocupar el solio presidencial-: "sus comunicaciones han sido admirables y por ellas merece Ud. no sólo un 'homenaje de la gratitud nacional' como dirá el respectivo decreto de honores póstumos que Ud. se ha ganado, sino también un puesto de precedencia (precedencia es consonante de presidencia) al del Doctor y amigo Alfonso López" [...]"135. Sin duda Restrepo identificaba en las gestiones de Santos, más que en las de López Pumarejo, las bases de la exitosa negociación finalmente suscrita:

Al Dr. López [con su intervención ante el presidente peruano Benavides] pudo haberle pasado lo que cuenta mi yerno Fernando González de un loco en Marsella: se le ha metido al loco que él lo rige y lo gobierna todo, y, para probarlo, se sube a un tranvía, saca el cuerpo hacia afuera, hace ademanes de comando y después de que el tranvía ha parado, ordena: Pare. Dice Fernando que ser profeta de para atrás es muy fácil ${ }^{136}$.

Para Restrepo, Colombia no desistía de nada al recibir formalmente el dominio sobre Leticia, pues lo que el Protocolo examinó -y terminó validando- no fueron las "legítimas aspiraciones" manifestadas por el Perú, sino otras realidades jurídicas siempre aceptadas en los términos del derecho internacional. Una y otra cosa diferían profundamente: si pasado un año no se promovían acciones concretas por el Perú, Colombia contaba ahora con una adecuada postura moral y material para proseguir la guerra. Ello implicaba el reconocimiento del Tratado Salomón-Lozano, el retiro de los ejércitos de la frontera, el restablecimiento de actividades diplomáticas entre los dos países, la instauración de un régimen aduanero, y la libre navegación de los ríos fronterizos ${ }^{137}$. En opinión del expresidente Restrepo, la soberanía sobre el puerto amazónico le adjudicaba al país una postura ética digna del aprecio de las naciones cultas, hecho concreto que históricamente jamás le otorgaron sus inveterados conflictos partidistas, ni la sórdida actuación de una sucesión de caudillos políticos que, invocando intereses regionales y personales, mañosamente los propiciaron ${ }^{138}$. En esos

\footnotetext{
${ }_{133}$ Carta de Carlos E. Restrepo a Marco Tobón Mejía, Roma, 28 de enero de 1933, A/CER/CE 74B/262:366.

${ }^{134}$ Carta de Carlos E. Restrepo a Eduardo Santos, Roma, 26 de enero de 1933, A/CER/CE 74B/240:333.

${ }^{135}$ Carta de Carlos E. Restrepo a Eduardo Santos, Roma, 4 de febrero de 1933, A/CER/CE 74B/237:328.

${ }^{136}$ Carta de Carlos E. Restrepo a Eduardo Santos, Roma, 27 de junio de 1933, A/CER/CE 74B/222:302.

${ }^{137}$ Pedro López Gómez, "El capitán Francisco Iglesias Brage en Leticia. Un gallego properuano en la Comisión de Administración del Territorio (1933-1934)”, Anuario de Estudios Americanos 58, no. 2 (2001): 606.

${ }^{138}$ Carta de Carlos E. Restrepo a Jaime Holguín, Roma, 28 de junio de 1933, A/CER/CE 74B/72:100.
} 
términos concluyó 1933, y aunque Restrepo experimentaba complacencia por el desenlace final del Conflicto, manifestaba aflicción frente al curso de la política interna, capaz de abrazar intereses genuinamente nacionales sólo si se producía una agresión externa, distando de toda convivencia pacífica y civilizada ${ }^{139}$. La firma del Protocolo de Río de Janeiro también fue registrada por el expresidente en epístola que dirigió a Agustín Nieto Caballero: "Hemos gozado lo indecible con el arreglo colombo-peruano y por el éxito merecen toda gratitud Ud., el Dr. Santos y los que a él han contribuido. Es seguro que la pasión política los insultará, pero qué insultos tan honrosos y codiciables"140.

Restrepo, que trabajó discreta pero mancomunadamente con el equipo diplomático colombiano que actuó en Ginebra, suministró sin duda versados consejos y observaciones idóneas, que contribuyeron a puntualizar el Acuerdo firmado. De ese modo, aportó al cierre de un interesante capítulo de la historia americana, como lo señaló él mismo:

La impresión general que nos ha producido a los colombianos de aquende el mar [es decir, residentes en Europa] el arreglo del Conflicto colombo-peruano, ha sido de descanso y satisfacción: por medio de la Corte de La Haya, cuya jurisdicción han aceptado casi todos los países civilizados, se aleja la catástrofe inimaginable de una guerra que perderían aún los mismos vencedores [...]

Es seguro que nuestros partidos tomaran pie en el arreglo para la diatriba implacable o para la alabanza desmedida. Para eso sirven: para trabajar por sus intereses por sobre los fueros externos de la patria. Así, tenemos paz y el país podrá convalecer de sus quebrantos nacionales e internacionales" 141 .

\section{Conclusiones.}

La historia escrita colombiana referida al Conflicto binacional -prácticamente la única expuesta en el país-, concuerda cabalmente con las posturas y argumentos mantenidos sobre el particular por personalidades y círculos políticos, empresariales e intelectuales de la época, según lo evidencia el Archivo de Carlos E. Restrepo. La viva voz de aquellas personalidades y círculos decisorios da cuenta, -sin reservas ni eufemismos-, de un nacionalismo colombiano que se preciaba de "ajustarse a la rectitud", a la vez que identificaba las posturas entonces adoptadas por el Perú, como “apartadas del deber ser”. Con

${ }^{139}$ Carta de Carlos E. Restrepo a Enrique Olaya Herrera, Roma, 8 de noviembre de 1933, A/CER/CE 74B/148:197.

${ }^{140}$ Carta de Carlos E. Restrepo a Agustín Nieto Caballero, Roma, 22 de mayo de 1934, A/CER/CE 75/184:258.

${ }^{141}$ Carta de Carlos E. Restrepo a Francisco Escobar, Roma, 12 de junio de 1934, A/CER/CE 75/57:77. 
su accionar -sumado a actitudes precedentes-, esa nación habría obligado a Colombia a sobrellevar, en el mejor de los casos, una convivencia más forzada que razonable. Fuentes secundarias y correspondencia examinadas, enmarcan las diferencias fronterizas en el origen mismo de uno y otro Estado, circunstancia que resultaría pertinente estudiar con profundidad y amplitud en el caso de múltiples países latinoamericanos.

A pesar del peso específico ejercido por el Conflicto binacional, su génesis y desarrollo parecen haber quedado en Colombia restringidos a un relativo olvido. En el presente, cuando el país afronta una vez más viejas pero irresueltas discusiones fronterizas con otros Estados (Nicaragua por ejemplo), poco se rememora un conjunto de eventos que indudablemente excitó ánimos y sensibilidades, conmocionando el ser nacional y dando pie a extensos análisis y sentires que reposan en la prensa y en múltiples archivos públicos y privados. Se trató de una coyuntura que movilizó cuantiosos recursos en pro de nuevos entendimientos diplomáticos, de la revaluación de la dinámica militar, de la consolidación misma del Estado colombiano -y de su gobierno-; y, lo más importante, de una inusual pasión patriótica que se proyectó alcanzando una intensidad nunca antes vista.

\section{BIBLIOGRAFÍA}

\section{Fuentes primarias}

Archivo Carlos E. Restrepo (A/CER), Fondos Correspondencia Enviada (CE) y Correspondencia Recibida (CR). Medellín, Biblioteca Central Universidad de Antioquia. República de Colombia. Protocolo de Río de Janeiro. Texto del protocolo. Proyecto de Ley y exposición de motivos. Bogotá: Imprenta Nacional, 1934.

SALOMÓN, Alberto y Fabio LOZANO TORRIJOS. Tratado de Límites y Navegación Fluvial entre las Repúblicas de Colombia y Perú (Tratado Salomón-Lozano). Bogotá, Imprenta Nacional, 1979.

Sociedad Geográfica de Colombia. Consultado el 15 de diciembre de 2015.

http://www.sogeocol.edu.co/Ova/fronteras_evolucion/documentos/arreglo_limites_colombi a_peru.pdf

\section{Fuentes secundarias}


ARANGO DE TOBÓN, María Cristina. Publicaciones periódicas en Antioquia 1814-1960: del chibalete a la rotativa. Medellín: Universidad EAFIT - Fondo Editorial Universidad EAFIT, 2006.

ARCINIEGAS RUEDA, Pedro. "Triunfo militar, empate diplomático". Revista Semana, 1 de septiembre de 2012. Consultado el 16 de agosto de 2015. http://www.semana.com/nacion/articulo/triunfo-militar-empate-diplomatico/263965-3.

Biblioteca Virtual Luis Ángel Arango. "Combate de Tarapacá”. Consultado el 25 de noviembre de 2013. http://www.banrepcultural.org/node/98004.

CAICEDO CASTILLA, José J. "Historia Diplomática”. Historia extensa de Colombia, vol. XVII. Bogotá: Lerner, 1974.

CASEMENT, Roger. El libro azul británico. Informes de Roger Casement y otras cartas sobre las atrocidades en el Putumayo. Londres: Editorial IWGIA, 1912.

CAVELIER GAVIRIA, Jorge. "Clínica Marly: 90 años de servicio al país”. El Tiempo, 18 de febrero de 1994. Consultado el 5 de diciembre de 2016. http://www.eltiempo.com/archivo/documento/MAM-44946.

DEL REAL DE GANDÍA, Segismundo. La Sierra Nevada y los orfelinatos de La Guajira. Bogotá, Imprenta Nacional, 1912.

DONADÍO, Alberto. “Colombia expulsa a los peruanos de Tarapacá”. Colombiamanía. Consultado el 5 de diciembre de 2016.

http://www.colombiamania.com/historia/index_historia/07_otros_hechos_historicos/0210_ guerra_peru.html.

EASTMAN, Jorge Mario (Compilador). “Eduardo Santos”, Obras selectas. Bogotá: Fondo de publicaciones de la Cámara de Representantes, 1981.

Periódico El Tiempo, “Hace 50 años”. Consultado el 30 de noviembre de 2013.

http://news.google.com/newspapers?nid=1706\&dat=19841222\&id=ObsqAAAAIBAJ\&sjid =9WcEAAAAIBAJ\&pg=3508,2006030.

NAJAR, Fernando. "Benjamín Saldaña en el recuerdo". Consultado el 14 de noviembre de 2013. http://diariodeiqt.wordpress.com/2009/04/15/benjamin-saldana-en-el-recuerdo/.

FORERO BENAVIDES, Abelardo. "El 13 de junio de 1953. Un día con 3 presidentes:

Urdaneta, Gómez y Rojas Pinilla”. Credencial Historia no. 6, (junio de 1990). 
GONZÁLEZ DÍAZ, Andrés. "Ministros bajo la presidencia de Enrique Olaya Herrera". Ministros del siglo XX. Primera parte. Consultado el 14 de diciembre de 2016. http://www.banrepcultural.org/blaavirtual/todaslasartes/obrames/ministros/ministros13.htm

HARDENBURG, Walter E. El paraíso del diablo. Londres: Editorial F. Truth, 1909. HERNÁNDEZ RODRÍGUEZ, Sandra Milena. “Análisis de las estrategias de actores nacionales e internacionales en la firma de los acuerdos diplomáticos suscritos entre Perú y Colombia en 1934 y su incidencia en la resolución del conflicto bilateral". Monografía de grado para optar al título de Internacionalista, Facultad de Relaciones Internacionales, Universidad Colegio Mayor de Nuestra Señora del Rosario, Bogotá, 2010.

Instituto Nacional de Cancerología, "Reseña histórica". Consultado el 11 de diciembre de 2016. http://www.cancer.gov.co/rese\%C3\%B1a-hist\%C3\%B3rica-inc.

LÓPEZ DE MESA, Luis. "Breve comentario inicial”. Historia de la Cancillería de San Carlos. Bogotá: Imprenta del Estado Mayor General, 1942.

LÓPEZ GÓMEZ, Pedro. "El capitán Francisco Iglesias Brage en Leticia. Un gallego properuano en la Comisión de Administración del Territorio (1933-1934)". Anuario de Estudios Americanos, 58, no. 2 (2001).

MARTÍNEZ SIMANCA, Albio. José Félix Fuenmayor. Entre la tradición y la vanguardia. Bogotá: Observatorio del Caribe Colombiano, 2011.

MEJÍA CUBILLOS, Javier. Diccionario biográfico y genealógico de la élite antioqueña y viejocaldense. Medellín: Universidad de Antioquia, Departamento de Economía, 2011.

PERRY, Oliverio. Quién es quién en Colombia. Bogotá: Perry Oliverio \& Cía. Editores. Argra, 1961.

PLAZAS OLARTE, Guillermo. “Conflicto con el Perú, 1932-1934”. Historia de las fuerzas militares de Colombia, tomo III. Bogotá: Planeta, 1993.

RESTREPO, José Manuel. Diario político y militar, Tomo I. Bogotá: Imprenta Nacional, 1954.

RIPOLL, María Teresa. "Diego Martínez Camargo, Pionero de la industria petrolera en el caribe colombiano". Huellas no.62 (2001).

Cuadernos de Historia Económica y Empresarial no. 2 (1999). 
RIVAS, Raimundo. Historia Diplomática de Colombia (1810-1934). Bogotá: Imprenta Nacional, 1961.

RIVERA, José Eustasio. La Vorágine. Bogotá: El Áncora Editores, 1989.

SANTOS MOLANO, Enrique. "La Mision Kemmerer". Credencial Historia no. 184 (abril de 2005). Consultado el 15 de diciembre de 2015.

http://www.banrepcultural.org/blaavirtual/revistas/credencial/abril2005/mision.htm.

Sin firmar. "Las guerras con el Perú". Credencial Historia no. 191 (noviembre de 2005).

Consultado el 15 de diciembre de 2015.

http://www.banrepcultural.org/blaavirtual/revistas/credencial/noviembre2005/guerras_peru. htm.

SOLANO DE LAS AGUAS, Sergio Paolo. Puertos, sociedad y conflictos en el Caribe colombiano, 1850-1930. Bogotá: Observatorio del Caribe Colombiano-Universidad de Cartagena, 2003.

THOMSON, Norman. El Libro Rojo del Putumayo. Bogotá: Arboleda\&Valencia, 1913.

TIRADO MEJÍA, Álvaro. “López Pumarejo: La Revolución en Marcha”. En Nueva Historia de Colombia, Vol. I, (Dir.) TIRADO MEJÍA, Álvaro. Bogotá: Planeta, 1989.

VALENCIA TOVAR, Álvaro. "Historia militar contemporánea”. En Nueva Historia de Colombia, Vol. II, (Dir.) TIRADO MEJÍA, Álvaro. Bogotá: Planeta, 1989.

VALLEJO M., Maryluz. "El Grito de Irreverencia del Gil Blas". Revista de Estudios Sociales no. 38 (enero de 2011).

VILLA QUINTERO, Fernando. "Hinestrosa Daza, Ricardo”. En: Gran Enciclopedia de Colombia, Vol. 17, (Dir.) WILLS FRANCO, Fernando. Bogotá: Casa Editorial El Tiempo Círculo de Lectores, 2007. 